$$
\begin{array}{cc}
\text { RFC FIVED } & \begin{array}{c}
\text { BNL-62224 } \\
\text { INFORMAL }
\end{array} \\
\text { DCT } 231995 & \\
\text { UST I } &
\end{array}
$$

\title{
BIOMONITORING FOR THE PHOTOVOLTAICS INDUSTRY
}

Nicole M. Bernholc and Paul D. Moskowitz

July 1995

Biomedical and Environmental Assessment Group

Analytical Sciences Division

DEPARTMENT OF APPLIED SCIENCE

,)
BROOKHAVEN NATIONAL LABORATORY UPTON, LONG ISLAND, NEW YORK 11973 


\section{DISCLAIMER}

This report was prepared as an account of work sponsored by an agency of the United States Government. Neither the United States Government nor any agency thereof, nor any of their employees, not any of their contractors, sub- contractors, or their employees, makes any warranty, express or implied, or assumes any legal liability or responsibility for the accuracy, completeness, or usefulness of any information, apparatus, product, or pro ess disclosed, or represents that its use would not infringe privately owned rights. Reference herein to any specific commercial product, process, or service by trade name, trademark, manufacturer, or otherwise, does not necessarily constitute or imply its endorsement, recommendation, or favoring by the United States Government or any agency, contractor, or subcontractor thereof. The views and opinions of authors expressed herein do not necessarily state or reflect those of the United States Government or any agency, contractor or subcontractor thereof. 


\section{DISCLAIMER}

Portions of this document may be illegible in electronic image products. Images are produced from the best available original document. 


\title{
Biomonitoring for the Photovoltaics Industry
}

\author{
Nicole M. Bernholc and Paul D. Moskowitz
}

July 1995

Prepared for:

Photovoltaic Energy Technology Division

U.S. Department of Energy

Washington, DC

Biomedical and Environmental Assessment Group

Analytical Sciences Division

Department of Applied Science

Brookhaven National Laboratory

Upton, NY 11973

This research was performed under the auspices of the United States Department of Energy under Contract No. DE-AC02-76CHO0016 


\section{TABLE OF CONTENTS}

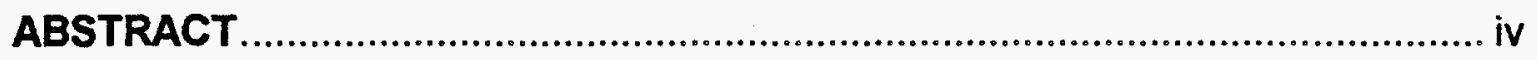

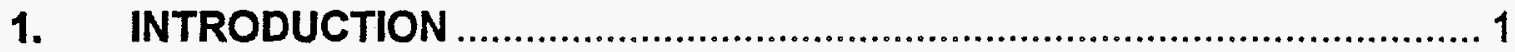

2. OVERVIEW

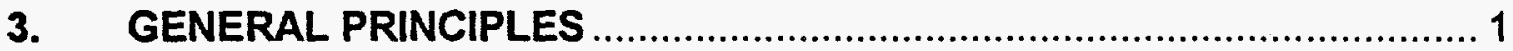

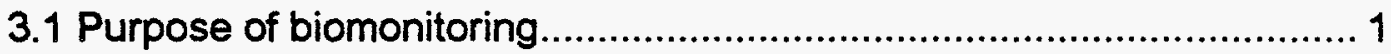

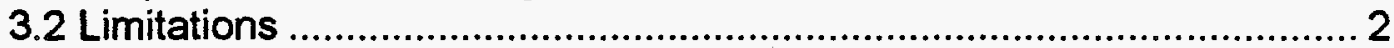

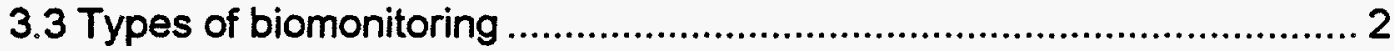

3.4 Reference values and interpretations ............................................. 3

3.5 Sources of variability and quality assurance ..................................... 3

3.5.1 Field quality control ....................................................... 4

3.5.2 Laboratory quality control .................................................... 5

3.5.3 Precautions for biological sampling for metals ..................... 6

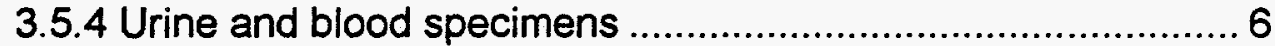

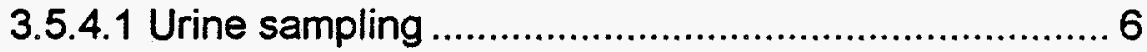

3.5.4.2 Blood sampling....................................................... 7

3.6 Frequency and timing of monitoring .............................................. 7

4.0 STANDARDS AND THE BIOLOGICAL MONITORING FOR PHOTOVOLTAIC

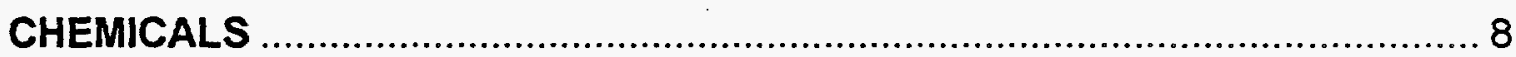

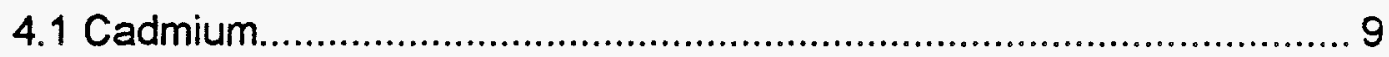

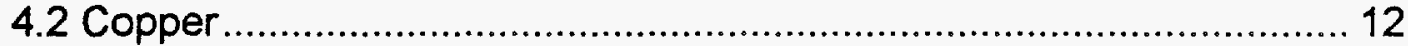

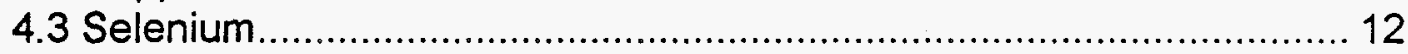

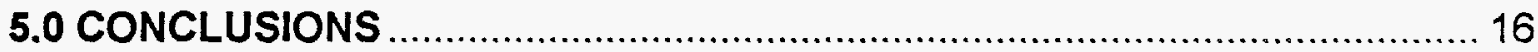

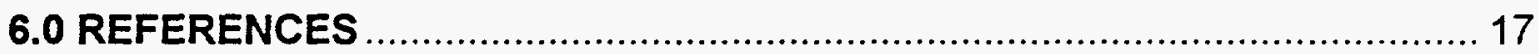

\subsection{APPENDICES}

Appendix A. Occupational Biomonitoring Procedures............................. 20

Appendix B. Types of Biomarkers ........................................................... 26

Appendix C. Selection of Sampling Methodologies ................................ 33

Appendix D. Protocol for Collecting Biological Specimens to Determine Metal Content ................................................ 35

Appendix E. Reference Values for Adducts in Urine ............................... 37

Appendix F. NIOSH Method 8310 Metals in Urine ................................... 38

Appendix G. NIOSH Method 8005 Elements in Blood or Tissue ................ 44

Appendix H. A Method for determination of Urine Selenium

Le Centre de Toxicologie du Quebec.................................... 51 
Appendix I. Method for determination of Serum Selenium Le Centre de Toxicologie du Quebec.

Appendix J. Method 27 - Determination of Selenium in Human Tissues, Fluids and Excreta by Hydride Generation and Atomicabsorption Spectrometry

Appendix K. Method 28 - Determination of Selenium in Plasma and Serum by Electrothermal Atomization-Atomic Absorption Spectrometry.

Appendix $L$ Method 29 -Determination of Selenium in Whole Blood and Other Biological Materials by Spectrofluorimetry 69

\section{TABLES}

Table 1. Categorization of Biological Monitoring Results Applicable through 1988 only

Table 1A Categorization of Biological Monitoring Results Applicable Beginning January 1, 1999. 10

Table 2. Actions Determined by Biological Monitoring 11

Table 3.

Noranda Copper Smelting \& Refinery - Selenium Biological Monitoring Criteria and Frequency of Monitoring

Table 4. Xerox - Selenium Biological Monitoring Criteria and Frequency of Monitoring 


\section{ABSTRACT}

Biomonitoring is a method for estimating the exposure of an individual, and it can be an valuable addition to a safety and health program. OSHA requires biomonitoring for a limited number of chemicals as part of an ongoing medicalmonitoring program. Several Biomonitoring requirements for Photovoltaics manufacturers are discussed as well as problems in interpretation and analysis when there is no guidance. Protocols, sampling, and analytical procedures for biomonitoring are included. 


\section{INTRODUCTION}

Biomonitoring often is used as a method for estimating the dose to an individual. Therefore, a parameter of measurement, or biomarkers must be identified. The purpose of this paper is to give an overview of biomonitoring protocols for metals used in the photovoltaics industry. Special attention is given to areas that often are skimmed over, to gain insights into some of the problems that may arise when these tasks are carried out.

\section{OVERVIEW}

Biological monitoring can be used to determine current human exposures to chemicals, as well as to detect past exposures, and the effects that these exposures may have on human health. It is used in conjunction with environmental monitoring to describe more completely worker's exposures to, and absorption of, chemicals in the workplace. Biological specimens (e.g., blood, hair or urine) are analyzed for chemical agents, metabolites, or for some specific effect on the person (Lowry 1994). Biomonitoring can assess a worker's exposure to industrial chemicals by all routes including skin absorption and ingestion. Although the methodology still is in its infancy, in cases where the procedures have been developed, it can be an invaluable component of an ongoing program of industrial hygiene monitoring. Like any technology, there are limitations to its effectiveness because of a lack of knowledge, contamination of specimens, and the introduction of errors.

\section{GENERAL PRINCIPLES}

\subsection{Purpose of biomonitoring}

Information from biomonitoring can serve many purposes. From a medical standpoint, biomonitoring traditionally is used in the field of public health to establish a baseline health status for patients and to determine their existing physiological condition, or any change in their health status. Biomonitoring can identify populations at risk, e.g., by blood-pressure screenings, glaucoma testing, so that treatments can be implemented. Occupationally, it can be used to detect changes in health status, as a supplemental means for reviewing the adequacy of protective measures in limiting personnel exposure, including engineering controls and work practices; also, it serves as an indicator if these controls fail, due to factors such as process changes, failure of controls, new or high hazard operations, or accidents (WHO 1993). Additionally biomonitoring is used to: 
Confirm remedial measures, e.g. reduced exposure to lead,

- Evaluate high hazard operations, by monitoring before, during, and after the exposure,

- Identify genetically linked or acquired susceptibility to specific chemicals or their metabolites (e.g., sensitization to toluene diisocyanate), thereby providing an opportunity for recognizing and protecting sensitive individuals.

Unlike environmental monitoring, biological monitoring should be considered a medical procedure because, by definition, the specimen comes directly from a human. Therefore, such areas as informed consent, medical-legal ethics, and the Federal Privacy Act need to be considered before any biomonitoring is undertaken.

\subsection{Limitations}

A major limitation to biomonitoring is the lack of detailed information on the fate of industrial chemicals in humans. Most toxicological/ pharmacological information is from experimental animals and is not easily applied to humans. Another concern is the wide variability seen in most biological monitoring data. Proper knowledge of the fate of a chemical, its pharmacokinetic properties, specific sampling and analytical methodologies, and quality-control procedures can control some variability; however, lack of consistency in specific methodology and in the interpretation of data remains an obstacle to its widespread use (ACGIH 1994).

\subsection{Types of Biomonitoring}

Biological monitoring can provide the occupational health professional with a tool for assessing a worker's exposure to chemicals. The measurement is made on some specimen collected from the worker at specified times. In the United States, the American Conference of Governmental Industrial Hygienists (ACGIH 1994) has set Biological Exposure Indices (BEls) for certain chemicals to serve as reference values. The recognized occupational biomonitoring procedures used in the United States are listed in Appendix A and compared to others used internationally. This list does not give all the common tests for medical diagnoses.

During biological monitoring, exhaled air, urine, blood, or other specimen is collected from the exposed person and analyzed for either the chemical itself, its metabolite(s), or characteristic, reversible, biochemical changes induced by the chemical. The sampling methodology is critical since the measurement can indicate either the intensity of a recent exposure, an average daily exposure, or a chronic cumulative exposure. Recommendations on biological exposure require a knowled $\mathrm{e}$ of the absorption, elimination, and metabolism of a chemical and how these correlate with biological effects. Human data from controlled experiments and field studies are used to uncover these relationships. 
The ACGIH recommends that biological monitoring be used to complement air monitoring, not as a primary control. It can substantiate air monitoring, and check the effectiveness of personal protective equipment, controls, and work practices. OSHA includes requirements for biological monitoring in its regulations for a few substances including, mercury, lead, and cadmium.

Biological monitoring can be classified into three types of indices: exposure, effect, and susceptibility (Hewitt and Sanderson, et al. 1993)(WHO 1994). The ACGIH BEls generally are used to complement airborne monitoring, but may be effect indices as well (1994). Effect indices are biochemical or other alterations which can be related to an established or potential health impairment. A susceptibility index relates to an inherent or acquired limitation of the individual to respond to an exposure by demonstrating hypersensitivity. There are many ethical considerations in using this type of tool in work situation. Appendix B lists biomarkers and what they measure.

\subsection{Reference Values and Interpretations}

Widely divergent reference values often are reported for trace elements in human samples, e.g. blood plasma, serum, and urine (Fishbein 1987; IARC 1986). Therefore, it is extremely important that good quality-assurance programs are established for sampling programs and analytical procedures.

Interpreting data is difficult because of the lack of standards or regulations on biological monitoring tests. The results obtained often depend on the time of collection, the specimen's integrity, drug or chemical interference, or methodologies. Finding measurable levels of an occupational chemical metabolite in a biological fluid which normally is not present is only an indication of exposure. Further testing, or examining the worker is needed to define health risk.

One approach to interpreting data is to collect specimens from non-exposed control subjects at the workplace, and to use the mean value from this group as a baseline to interpret the values from an exposed population. When such a group cannot be obtained, using an outside control group may be an option. While the literature contains normal or non-exposed values and may suggest values for "limits," these numbers should be used cautiously since they apply to a particular laboratory method and sampling strategy. NIOSH has 'guidance on interpretation with each of their methods; however, these values are not the recommended limit and should be evaluated by a qualified health professional (Lowry 1994).

\subsection{Sources of Variability and Quality Assurance}

For any chemical exposure, the uptake can vary in each individual depending on the route of exposure, the physical form and solubility of the chemical, its concentration and the duration of exposure, as well as skin characteristics. All these parameters can be affected by environmental factors, such as the presence of other chemicals in the 
environment; furthermore, diet may induce or inhibit metabolizing enzymes. Additionally, people themselves vary; genetics, age, body size, and sex play important roles in the metabolism of some drug and chemicals. Variability can be introduced because the samples were collected inadequately and the analysis, poor. Appendix $C$ gives a checklist for selecting appropriate methodologies. The selection should involve an occupational health professional familiar with the workplace, a competent laboratory chemist, and a physician knowledgeable in occupational medicine.

Many authors and organizations emphasize the importance of analytical quality assurance (Smith and Bolyard 1994); (Elinder 1986); (Fishbein 1987); (Cadmium Standard, 1992); and, (Friberg 1988). To assure valid results, quality control should be integrated as a standard part of the analytical work. Good data require having an effective quality-control program during both laboratory analysis and the collection process.

\subsubsection{Field Quality Control}

Field personnel should be familiar with the methods of sampling and measurement (Smith and Bolyard 1994). The methods usually specify the proper media to be used, the correct flow rate and sample volume, and provide possible sources of interferences, as well as special precautions on handling and shipping the samples.

Contaminating the sample is the primary source of error when concentrations are in the nanogram or subnanogram level. Large errors can be avoided by working in controlled clean environments or by using specially selected containers and meticulously cleaned laboratory instruments.

Special care must be taken to avoid contaminating field samples. They must not be stored or shipped with bulk materials which might spill or otherwise cause contamination. The glassware or other containers for sampling and shipping should be cleaned following procedures recommended in the analytical method.

Field blanks are used to estimate contamination which may occur immediately before and after sampling, during shipment, or while awaiting measurement in the laboratory.

Quality control at the field level can be maintained and checked in the laboratory by:

(1) ensuring integrity of the sample, i.e., using the proper procedures for collecting, preserving, and shipping it;

(2) submitting blind, duplicate-split samples to the laboratory, identifying each specimen as a normal field sample; and 
(3) including control samples from non-exposed workers.

Evaluating these data and comparing values from control populations to published data or their own historical control data will provide health practitioners with useful information on the integrity of the data.

\subsubsection{Laboratory quality control}

Many references discuss the components of a good laboratory quality-control program and the requirements for performing analyses in qualified analytical laboratories. Some standards specify a quality-control program as part of the regulation. In 29 CFR 1910.1027(I)(1)(iv) of the Cadmium Standard, 1992 OSHA specifies "analysis... is performed in laboratories with demonstrated proficiency for that particular analyte..." Appendix $F$ of that standard - Non-mandatory protocol for biological monitoring - has extensive guidance on selecting a laboratory and verifying of the results. The purpose of the protocol was to set out procedures for establishing and maintaining the quality of results obtained from analysis of cadmium in blood (CDB), cadmium in urine (CDU, beta-2-microglobulin in urine (B2MU), and creatinine in urine (CRTU).

Assessing inter- and intra-laboratory testing is a large component of this program. Intra-laboratory variability can be estimated from the results of analysis of blind samples; however, inter-laboratory testing requires the cooperation and coordination of several independent laboratories. Inter-laboratory testing also can be useful for defining the relationship of data reported by different laboratories using either the same or different measurement techniques, and also for uncovering errors in methodology or identifying critical steps in the procedures. For assessment of many metals analyses, inter-laboratory testing programs have not been available.

The National Institute for Occupational Safety and Health (NIOSH) operates a Proficiency Analytical Testing (PAT) Program that is useful for measuring a laboratory's performance on a variety of common industrial hygiene samples, including solvent vapors on charcoal tubes and metals, asbestos, and silica on filters. Laboratories undertaking industrial hygiene analyses are strongly encouraged to participate in this program.

Similarly, the American Industrial Hygiene Association (AIHA) operates a laboratory accreditation program for industrial hygiene laboratories. Site visits and application reviews can be very useful for assessing of a laboratory's overall quality assurance system, as well as the adequacy of personnel, facilities, and equipment.

However, there are no PAT programs for many metals. Just because programs participate in a PAT procedure does not mean that the program is specific for the analyte. When the cadmium standard was published, there was no program in the 
United States. OSHA recommended that laboratories participate in the PAT program operated by the Centre du Toxicologie du Quebec (CTQ) or an equivalent one. CTQ also has a PAT program for selenium. Similarly, proficiency testing for creatinine in urine (CRTU) is recommended. Only the College of American Pathologists (CAP) currently conduct proficiency testing for CRTU. It is recommended that the physician/industrial hygienist review the results of proficiency evaluations made by the PAT and CAP, as well as the results of their internal quality assurance/quality control program for each analytic procedure. The responsible physician can identify laboratories most likely to be proficient in analysing samples for monitoring of cadmium and CRTU. This recommendation can be applied to the evaluation of all biological monitoring data.

\subsubsection{Precautions for Biological Sampling for Metals}

Special precautions should be used when sampling for metals because normal collection equipment may contain trace amounts of the metal in question. Analytical laboratories should have special protocols for sampling and handling these types of samples, including special containers, and solvents. Appendix D gives an example of such a protocol.

\subsubsection{Urine and Blood Specimens}

\subsubsection{Urine Sampling}

Collecting urine specimens is an non-invasive procedure. The chief problems with such samples include the time of collection and possible contamination, or tampering with the sample. Procedures for collecting them are listed in the ACGIH Documentation of Threshold Limit Values (TLVs), OSHA's Technical Manual, specific OSHA standards, and NIOSH's Manual of Analytical Procedures. Samples can be easily biased by contamination in the workplace: the donor should shower and change clothes before sampling (ACGIH 1994). The most influential factors are time of collection and the urine output. To control for the latter, ACGIH recommends using excretion rate rather than concentration. While measurements in 24-hr samples are more representative than isolated samples, and correlate better with the intensity of exposure, for practical reasons, most urine samples collected in an industrial environment represent "spot" sampling collected at pharmacokinetically correct times. Measurements are expressed in relation to total solids (measured by specific gravity) or creatinine concentration.

Data collected from urine should be corrected for the dilution of urine; however, there is wide variation in the reported methods of correction. In the industrial hygiene community, an accepted practice is to adjust the concentration to some standardized specific gravity, usually 1.024; however, the literature also shows 1.016 and 1.018 as "standards." Variations also result from different customs of standardization between the United States and other countries. Where damage results from exposure to heavy 
metals, urinary protein may increase, and so, when a specific-gravity correction is applied, would give a false low concentration. The medical/clinical community has long favored normalization based on the concentration of a normal urinary constituent, creatinine. Such units are $\mathrm{g}$ analyte/g creatinine, or $\mathrm{mg}$ analyte/g creatinine. This correction is gaining wide acceptance in Europe and within occupational health circles. Creatinine, a product of tissue breakdown, is excreted at a relatively uniform rate, and the total amount excreted per day is quite constant from day to day in a given individual. For BEls based on urine analysis, the variation in urine volume is very significant. Therefore, ACGIH determined that when concentration is important, BEIs are expressed in relative to creatinine excretion (ACGIH 1994). Appendix $E$ lists the reference parameters for urine adducts.

\subsubsection{Blood Sampling}

This method is invasive and can be performed only by medical personnel. Furthermore, blood can easily deteriorate when not stored and transported properiy. Laboratories should have specific protocols for collecting blood for heavy metal analysis. Generally, blood should be collected into an acid-washed "heavy metal-free" glass container to minimize contamination. In addition, because of potential for bloodborne exposures, the analyses require meticulously clean procedures (Appendix D).

The form of the analyte in blood should be considered. Analytes can be free, conjugated, or bound to protein. For determining the free fraction, specimens must be treated so that conjugated bonds are not broken. Similarly, if the concentration of the total contaminant is required, samples must be treated to release all bound forms of the compound.

\subsection{Frequency and timing of monitoring}

Unless stipulated by a particular regulation, the frequency of monitoring is up to the discretion of the employer. Regardless of the established frequency, the time of monitoring is based on the uptake and elimination rates of chemicals and their metabolites and the duration of the induced biochemical changes (ACGIH, 1994). For some chemicals, sampling time may have to be in relation to "prior to shift" (after 16 hours without exposure), "during shift," or "end of shift" (meaning the last 2 hours of exposure). Some chemicals may be rapidly eliminated and have a half-time of less than 5 hours. Other chemicals, with longer half-times, require sampling at the beginning of the workweek, or end of workweek (after two days without exposure following four or five consecutive working days with exposure); they accumulate in the body during the workweek, and therefore, sampling should be scheduled in relation to previous exposures. For chemicals with multiphase elimination, sampling should be scheduled considering both workday and workweek exposure. Lastly, the timing of sampling is not critical for compounds that have a very long elimination half-time, and accumulate in the body over years. 


\subsection{EXPOSURE STANDARDS AND THE BIOLOGICAL MONITORING FOR PHOTOVOLTAIC CHEMICALS}

OSHA and the ACGIH have set exposure limits for cadmium, tellurium, copper, indium, and selenium, the chemicals of major interest to the photovoltaics industry. Both the OSHA permissible exposure limit (PEL) and the ACGIH threshold limit value (TLV) are 8-hr, time-weighted average exposure concentrations to which nearly all workers can be exposed without adverse effects for a normal 8-hour work-day and a 40-hour work week. In 1992, OSHA lowered its cadmium PEL to $5 \mu \mathrm{g} / \mathrm{m}^{3}$. This revision was based on the determination that, at the previous exposure limit of $200 \mu \mathrm{g} / \mathrm{m}^{3}$, workers still faced a significant risk of developing lung cancer and serious kidney damage. The standard included a provision for a few industries where it is not feasible to achieve the PEL by engineering and work practice controls. In these cases, separate engineering (and work practice) control air limits (SECALs) of $15 \mu \mathrm{g} / \mathrm{m}^{3}$ and/or $50 \mu \mathrm{g} / \mathrm{m}^{3}$ were established as the lowest levels feasible above the PEL (29 CFR 1910.1027). The ACGIH designated cadmium as a suspect human carcinogen, and set a TLV of $0.01 \mathrm{mg} / \mathrm{m}^{3}$ for total cadmium dust, and $2 \mu \mathrm{g} / \mathrm{m}^{3}$ for respirable cadmium dust (ACGIH 1994). The former was set to prevent preclinical kidney dysfunction, while the recommendation for the respirable fraction was designed to prevent the development of lung cancer. OSHA considers all cadmium compounds to be toxic, and cadmium telluride was specifically included in the standard (personal communication, C. Freeman 1994). OSHA considered the data inadequate to develop public policy decisions that would allow some workers to be exposed to higher amounts of cadmium than other workers based upon type of cadmium compound alone; OSHA believes that differential toxicities are not adequately established, and there is little understanding of the underlying pharmacokinetics and decomposition. This lack makes evaluating the toxicity of mixtures of cadmium compounds difficult; therefore, OSHA chose to err on the side of workers' health by considering all cadmium compounds equally toxic, and regulated them under 29 CFR 1910.1027.

OSHA and ACGIH have set a workplace standard for tellurium at $0.1 \mathrm{mg} / \mathrm{m}^{3}$ to avoid systemic poisoning; however, garlic breath still may occur at this level.

For copper, the $8-\mathrm{hr} P E L$ is $0.1 \mathrm{mg} / \mathrm{m}^{3}$ as a fume, and $1 \mathrm{mg} / \mathrm{m}^{3}$ as a dust or mist. The ACGIH set a higher TLV for copper fume, $0.2 \mathrm{mg} / \mathrm{m}^{3}$, based on information that showed there were no adverse effects to levels of $0.4 \mathrm{mg} / \mathrm{m}^{3}$. This level was set to protect workers from irritation and systemic effects. The dust and mist values are 1 $\mathrm{mg} / \mathrm{m}^{3}$. The PEL and TLV for indium of $0.1 \mathrm{of} \mathrm{mg} / \mathrm{m}^{3}$ were based on data indicating - evere pulmonary toxicity from indium salts (ACGIH 1993). The selenium TLV and PEL of $0.2 \mathrm{mg} / \mathrm{m}^{3}$ as selenium were set to prevent systemic toxicity and to minimize the potential of ocular and irritation to the upper respiratory tract. Hydrogen selenide has an 8 -hr TLV of $0.05 \mathrm{mg} / \mathrm{m}^{3}$ to prevent irritation and prevent the onset of chronic hydrogen selenide-related disease. The sites in the body that are most sensitive to selenium include the central nervous system, liver, spleen, and respiratory system. 
Overt symptoms caused by excessive exposure to selenium include skin burns, dermatitis, garlic odor on the breath, a metallic taste in mouth and nail and hair loss. Selenium may elevate liver function tests, irritate the respiratory tract, and cause neurological symptoms including frontal headache, nervousness, dizziness, coma, and toxic polyneuritis.

Of the above group of metals, biological monitoring is specified by OSHA only for cadmium (29 CFR 1910.1027 Cadmium). Appendix F-Non-mandatory protocol for biological monitoring - identifies the specific protocols to be used. However, there are procedures for monitoring of copper on a non-occupational basis, and for selenium in occupationally exposed workers (Vaillancourt 1994; Woodard 1994).

\subsection{Cadmium}

The OSHA cadmium standards requires biological monitoring for cadmium in blood (CDB), cadmium in urine (CDU), and beta-2-microglobulin in urine (B2MU). Additionally, creatinine in urine (CRTU) must be determined because CDU and B2MU are normalized to this component of the urine.

To ensure the accuracy and reliability of laboratory analysis, OSHA recommends that the laboratory analyzing these samples participates in an ongoing proficiency testing program (see section 3.5.2 Laboratory Quality Control and Appendix F of 29 CFR 1910.1027 Cadmium standard). Acceptable analytical methods are identified for determining CDB, CDU, and CRTU. If laboratories use alternate methods of analysis, they should submit sufficient data to the responsible physicians to demonstrate that the method satisfies the defined quality objectives of the program.

Table 1 shows the actions triggered by cadmium biological monitoirng for an employee. The biological results for each employee determines the actions required for that person.

An employee is assigned category $A$ if ther results for all three biological markers fall at or below the levels listed in the table for category $A$, similarly for category $B$ and $C$. Table 2 gives the recommended follow-ups based on this categorization. 


\begin{tabular}{||l||c|c||}
\hline \multicolumn{3}{|c||}{ Table 1. Categorization of Biological Monitoring Results } \\
Applicable through 1988 only \\
\hline Biological marker
\end{tabular}

From 29CFR 1910.1027, Appendix A, Table A

\begin{tabular}{|c|c|c|c|}
\hline \multicolumn{4}{|c|}{$\begin{array}{c}\text { Table 1A Categorization of Biological Monitoring Results } \\
\text { Applicable Beginning January } 1,1999\end{array}$} \\
\hline \multirow[t]{2}{*}{ Biological marker } & \multicolumn{3}{|c|}{ Monitoring Results Categories } \\
\hline & $A$ & B & $\mathrm{C}$ \\
\hline $\begin{array}{l}\text { Cadmium in urine } \\
(\mathrm{CdU})(\mu \mathrm{g} / \mathrm{g} \text { creatinine })\end{array}$ & $\leq 3$ & $>3$ and $\leq 7$ & $>7$ \\
\hline $\begin{array}{l}\text { B2-microglobulin } \\
(B 2-M)((\mu g / g \text { creatinine })\end{array}$ & $\leq 300$ & 300 and $\leq 750^{*}$ & $>750$ \\
\hline $\begin{array}{l}\text { Cadmium in blood } \\
\text { (CdB) ( } \mu \text { g/liter whole blood) }\end{array}$ & $\leq 5$ & $>5$ and $\leq 10$ & $>10$ \\
\hline \multicolumn{4}{|c|}{$\begin{array}{l}\text { If an employee's B2-M levels are above } 750 \mu \mathrm{g} / \mathrm{g} \text { creatinine, in order for mandatory } \\
\text { medical removal io be required, either the employee/s CdU level must also be }>3 \mu \mathrm{g} / \mathrm{g} \\
\text { creatinine or CdB level must also be }>5 \mu \mathrm{g} / \text { /iter whole blood. }\end{array}$} \\
\hline
\end{tabular}




\begin{tabular}{|c|c|c|c|}
\hline \multirow[b]{2}{*}{ Required actions } & \multicolumn{3}{|c|}{ Monitoring Results Categories } \\
\hline & $\dot{A}^{1}$ & $\mathrm{~B}^{2}$ & $\mathrm{C}$ \\
\hline \multicolumn{4}{|l|}{ Biological monitoring } \\
\hline Annual & $x$ & & \\
\hline Semiannual & & $x$ & \\
\hline Quarterly & & & $\mathrm{x}$ \\
\hline \multicolumn{4}{|l|}{ Medical examinations } \\
\hline Biennial & $x$ & & \\
\hline Annual & & $x$ & \\
\hline Semiannual & & & $x$ \\
\hline Within 90 days & & $x$ & $x$ \\
\hline \multicolumn{4}{|l|}{ Assess within 2 weeks: } \\
\hline Excess cadmium exposure & & $x$ & $x$ \\
\hline Work practices & & $x$ & $x$ \\
\hline Personal hygiene & & $x$ & $x$ \\
\hline Respirator usage & & $x$ & $x$ \\
\hline Smoking history & & $x$ & $\bar{x}$ \\
\hline Hygiene facilities & & $x$ & $x$ \\
\hline Engineering controls & & $x$ & $x$ \\
\hline Correct within 30 days & & $x$ & $x$ \\
\hline Periodically assess exposures & & & $x$ \\
\hline Discretionary medical removal & & $x$ & $\bar{x}$ \\
\hline Mandatory medical removal & & & $x$ \\
\hline
\end{tabular}

'For all employees covered by medical surveillance exclusively because of exposures prior to the effective date of this standard, if they are in Category $A$, the employer shall follow the requirements of paragraphs (1) (3) (I) (B) and (1) (4) (V) (A) of the Cadmium Standard 29CFR 1910.1027. If they are in Category B or C, the employer shall follow the requirements of paragraphs (1) (4) (v) (B) - (C).

${ }^{2}$ See footnote Table 1. 


\subsection{Copper}

Copper serves primarily as a cofactor for oxidase enzymes, and is ubiquitous within cells, organelles, and plasma. It is biologically monitored as copper in urine, in blood, or as serum ceruloplasmin to confirm if the donor has Wilson's disease (copper oxidase).

There are NIOSH-approved methodologies for assessing copper in urine and blood. (Appendices F \& G - METALS in urine, METHOD: 8310; ELEMENTS in blood or tissue METHOD: 8005). These methodologies also applies to a large number of metals. A $50 \mathrm{ml}$ specimen is required, but the way in which it is collected is not specified. Analysis is done by inductively coupled argon plasma, atomic emission spectroscopy, and the results are reported as $\mu \mathrm{g} / \mathrm{g}$ creatinine. The Mayo Medical Laboratories also conduct these analyses by inductively coupled plasma emission spectroscopy (ICPE); however, they have a specific protocol for collecting samples for analysis. For urine, they recommend using $7 \mathrm{ml}$ from a 24-hour urine collection. Specimen are collected in acid-washed plastic jars with $20 \mathrm{ml}$ of $6 \mathrm{~N}$ nitric acid added immediately before collection is started; this adjusts the $\mathrm{pH}$ to 1.5-2.0. Specimens should be refrigerated or frozen. The Mayo Medical Laboratories do not report urine values as per $\mu \mathrm{g} / \mathrm{g}$, rather, they are expressed in terms of $\mu \mathrm{g} / \mathrm{specimen}$. The normal test values are 15-60 $\mathrm{g} / \mathrm{specimen}$ for a 24 -hour collection. Specimens other than $24-$ hour ones are reported in units of $\mu \mathrm{g} / \mathrm{L}$, for which normal values are not established (Mayo Medical Laboratories 1995.

Mayo Medical Laboratories also analyses serum copper and blood copper by ICPE following a collection protocol (i.e., use a stainless steel needle attached to a metal-free syringe without EDTA). The normal range of serum copper is $0.75-1.45$ $\mu \mathrm{g} / \mathrm{mL}$. The procedure involves collecting a syringe full of blood, allowing it to clot (approximately 30 minutes), and centrifuging up to $3,000 \mathrm{rpm}$. Two $\mathrm{ml}$ of serum are placed in metal-free, screw-capped polypropylene vials. Samples should be shipped under refrigeration. If they are stored for more than 48 hours, they should be frozen and sent on dry ice. Serum ceruloplasmin also can be determined. This test usually is done on persons suffering from Wilson's disease.

\subsection{Selenium}

While selenium can he detected in both blood and urine, urine samples are easier to obtain. The low concentrations of selenium $(\mathrm{ng} / \mathrm{g})$ in biological and environmental samples necessitate sensitive, accurate analytical techniques. Interlaboratory comparative studies have revealed problems both of accuracy and precision (Hogberg and Alexander 1986; Patel, pers comm 1994). Some selenium compounds are instable or volatile, especially when heated; this fact is important when storing or preparing the samples and preventing selenium loss (Bem 1981). Selenium can be 
accurately determined in biological samples by several different methods, provided the analyst is very well acquainted with the problems associated with the chosen method (Koirtyohann and Morris 1986; Weber, pers comm 1994). The results of interlaboratory comparisons find that, for any method, at least one laboratory reported an acceptable result. Participation in a PAT program ensures increasing the number of acceptable results and identifying problems of quality control (Weber 1994). Patel (1994) suggested that PAT analysis should include samples in the substrate to be tested, e.g., selenium analysis in urine and blood.

For samples in organic matrices, the sample must be treated to remove organic matter and release the selenium, as well as to bring it into a measurable oxidation state. This can be accomplished through wet digestion, predigestion, combustion, and fusion.

The detection limits of classical flame AAS techniques are not sufficiently low to be useful for determining selenium in biological samples. Hydride-generation atomicfurnace atomic-absorption spectroscopy is used preferentially. Graphite-furnace atomic-absorption spectroscopy offers high delectability $\left(5 \times 10^{-11} \mathrm{~g}\right.$ selenium $/ \mathrm{g}$ sample) but interference from the matrix can cause significant difficulties Nickel, molybdenum, or platinum commonly are added to the sample to thermally stabilize the selenium. Organic materials then are destroyed by high temperature in the furnace before atomizing the sample at very high temperatures $\left(2,700^{\circ} \mathrm{C}\right)$. The method relies on the fact that numerous metal compounds react with selenium compounds to form relatively refractory metal selenides. Corrections for background absorption include the deuterium continuum-light-source method, and Zeeman splitting of the absorption line. The latter is necessary for determining selenium in blood and blood products when this method is used because spectral interference from iron occurs at the wavelength of selenium, and cannot be corrected by a deuterium continuum source. Several techniques for determining selenium are shown in Appendices $H$ - $L$.

Wet digestion is most commonly employed to recover selenium in organic matter. Different methods have been used, but it was found that if nitric acid is used as an ingredient, Se can be recovered reproducibly only if all the acid is removed from the sample. The methods include different mixtures of nitric, sulfuric, and perchloric acids with or without additives, such as hydrogen peroxide, mercury, molybdenum, vanadium, or persulfate as stabilizers. If perchloric acid is included, good ventilation techniques and special hoods must be used to prevent explosions and the buildup of perchloric acid on surfaces. Selenium may be released into the air by heating seleniumcontaining materials (sublimation takes place from $170-180^{\circ} \mathrm{C}$ ). Often, complexing agents, such as oxalate or ethylenediaminetetraacetic acid, are used to prevent this loss.

Electrothermal atomic absorption is a highly sensitive measuring technique, but the sample must be treated to stabilize the volatile selenium during ashing, and chemical and spectral interferences from biological matrices occur. A Zeeman-based 
background correction eliminates these interferences, so that the metal can be determined directly in a variety of biological media (Hogberg and Alexander, 1986.) (Nackowski, 1989).

Thermal neutron activation is the commonest procedure for assessing irradiated samples containing selenium. The technique can be very accurate, sensitive, and specific; however, it requires sophisticated equipment that most laboratories do not have. Its most important use is as a reference method against which to evaluate other methods when good reagents are not available.

The selenium content in hair has not been generally measured, except in special circumstances where external contamination can be excluded. The presence of selenium compounds in anti-dandruff hair formulations can make this method problematical. However, new methodologies are being developed so that this technique may become viable (Suzuki 1988).

Blood-glutathione peroxidase activity may be useful for detecting selenium deficiency. The WHO found that it is inconclusive as a predictive value, though variation in glutathione peroxidase activity with different exposures was shown (WHO 1987).

Since 1979, the CCR Refinery of Noranda Copper Smelting and Refining has been monitoring worker exposures to selenium. They have had an established medical surveillance program since 1975 (Vaillancourt and Robin 1994). In 1989, they established an internal standard of exposure for selenium of $200 \mu \mathrm{g} / \mathrm{L}$ measured as urinary selenium. The table below shows the protocol for environmental monitoring.

\begin{tabular}{|l|l|}
\hline \multicolumn{2}{|c|}{$\begin{array}{l}\text { Table 3. Noranda Copper Smelting \& Refinery - Selenium Biological } \\
\text { Monitoring Criteria and Frequency of Monitoring }\end{array}$} \\
\hline Criteria & Frequency \\
\hline Airborne levels $>50 \%$ of the TLV & 6 months \\
\hline Airborne levels $<50 \%$ TLV & 12 months \\
\hline $\begin{array}{l}\text { Process change; abnormality during } \\
\text { medical monitoring }\end{array}$ & As needed \\
\hline
\end{tabular}

Medical monitoring is a supplement to environmental monitoring and serves as a backup indicator of a change in either processes or work practices, or failure of control systems. Medical evaluation/surveillance ide... fies workers who have pre-existing conditions that may be aggravated by exposure to selenium. Technically, the only medical conditions that would exclude a worker from contact with selenium or its compounds are major skin conditions, (uncontrolled exzema, active infections, proven allergy to selenium), and respiratory conditions (emphysema, asthma, and an inability to wear a respirator) though Noranda also excludes pregnant women. The annual 
examination includes bloodwork (blood urea nitrogen, complete blood count, serum creatinine, SGOT), liver tests to detect liver damage, pulmonary function testing, a medical questionnaire, and a physical examination. Periodic monitoring is performed every 6 months for the first two years. The sample is taken at the end of the workshift, either at the end of the work week or on day 3,4, or 5 of the work week. If selenium is below the limit of $200 \mu \mathrm{g} / \mathrm{L}$, then an annual monitoring schedule is instituted. Any level above $475 \mu \mathrm{g} / \mathrm{L}$ is considered toxic for short-term exposure without producing acute toxicity.

If process equipment malfunctions, employees are referred to the medical clinic and urine samples are taken immediately, and for the following 3 days, even if no clinical symptoms are detected. If clinical symptoms are detected (e.g., skin burns, dermatitis, garlic odor on breath, metallic taste in mouth, nail and hair loss), the worker is referred to a physician. Any levels above $200 \mu \mathrm{g} / \mathrm{L}$ are double-checked and then rechecked for five consecutive days. Samples are compared to pre-sample exposures and dietary ingestion of selenium-containing products is reviewed. Simultaneously, urinary samples are taken from all other workers and an environmental study is initiated to evaluate ambient air, process, ventilation, and work methods used.

If levels are above the maximum norm of $475 \mu \mathrm{g} / \mathrm{L}$ the worker is withdrawn from the exposure and given a complete medical examination and questionnaire. If there are no clinical symptoms, the worker can remain in the job, but must wear a respirator until the source of exposure is identified.

In 1971, Xerox also instituted a biological monitoring program for selenium (Woodard, 1994). The program serves as a secondary preventive measure to ensure the effectiveness of the primary control measures. Biological monitoring is implemented only after environmental health and safety personnel characterize the workplace tasks and exposures, and implement the use of engineering controls and personal protective equipment as required, along with developing an industrial hygiene sampling plan. The biological monitoring program complements the environmental measures and monitoring. While Xerox uses an upper limit of $100 \mu \mathrm{g} / \mathrm{l}$ (urine) selenium as a normal value, historically, even in their exposed populations, the values have never exceeded $50 \mu \mathrm{g} / \mathrm{l}$. The mean urine selenium for exposed employees is less than $32 \mu \mathrm{g} / \mathrm{l}$, and the mean urinary selenium in controls ranged from $24-32 \mu \mathrm{g} / \mathrm{l}$. The 100 $\mu \mathrm{g} / \mathrm{l}$ limit was selected because an evaluation of the literature did not record acute health effects at this level; no data on chronic effects were found. Consequently, the trigger for further investigation is $100 \mu \mathrm{g} / \mathrm{l}$ (urine) selenium, or twice the baseline level of selenium in urine, whichever is lower (Table 4).

When high values are found in workers, the sources are traced and an action plan is instituted. Elevated measurements have been attributed to failure of equipment, changes in work practice, and consumption of selenium-containing vitamin supplements. Levels returned to within the baseline when the vitamins were 
temporarily stopped. Xerox's program also identifies the work areas and job tasks involved in exposure to selenium.

\begin{tabular}{|l|l|}
\hline \multicolumn{2}{|c|}{$\begin{array}{c}\text { Table 4. Xerox - Selenium Biological Monitoring } \\
\text { Criteria and Frequency of Monitoring }\end{array}$} \\
\hline $\begin{array}{l}\text { Control Limit } \\
\text { Total urine selenium }<100 \mu \mathrm{g} / \mathrm{l} \text { or increase to } \\
\text { level less than two times baseline }\end{array}$ & \\
\hline Testing & $\begin{array}{l}\text { Action } \\
\text { Results and medical interpretation } \\
\text { sent to the employee }\end{array}$ \\
\hline Results < control limit & $\begin{array}{l}\text { Results discussed with employee and } \\
\text { follow-up action determined. } \\
\text { Safety department and supervisor } \\
\text { alerted and workplace evaluated. }\end{array}$ \\
\hline $\begin{array}{l}\text { Criteria for Testing } \\
\text { Potentially high exposure tasks } \\
\text { Routine Tasks }\end{array}$ & $\begin{array}{l}\text { Frequency } \\
\text { Twice per year for all employees in the } \\
\text { exposure group in work area. } \\
\text { Following } 2 \text { or more consecutive days } \\
\text { in the workplace. }\end{array}$ \\
\hline Employee requests & \\
\hline Selected operations & Before and after selected operations \\
\hline
\end{tabular}

\section{CONCLUSIONS}

There is a large body of literature on biological sampling. In the photovoltaics industry, biomonitoring can be a useful addition to an environmental monitoring program. It can be a secondary tool for validating the quality of engineering and workpractice controls. The integrity of data collection and analysis is a problematical issue, and good quality-assurance programs and reviews are important to ensure the success of this type of program. Case histories show the value of these programs. 


\section{REFERENCES}

ACGIH, (1994) American Conference of Governmental Industrial Hygienists. Documentation of the threshold limit values and biological exposure indices. Cincinnati, $\mathrm{OH}$.

Aitio, A. (1988). Biological monitoring, in: Biological Monitoring of Toxic Metals, Clarkson, T.W., L. Friberg, G, F. Nordberg, and P. R. Sager (eds). Rochester series on Environmental Toxicity. Plenum Press, NY.

Bem E. M. (1981). Determination of selenium in the environment and in biological material. Environ Health Perspect 37:183-200.

Bragt, W., C. M. Zwennis, and A. C. Granssen (1986). Biological monitoring of exposure to chromium (VI) salts: The role of solubility,. in: Handbook on the Toxicology of Metals, 2nd edition. Friberg, L., G. F. Nordberg and V. Vouk (eds.), Elsevier Science Publishing Company, N.Y..

Diamond, G. L. (1988). Biological monitoring of urine for exposure to toxic metals, in: Biological Monitoring of Toxic Metals, Clarkson, T. W., L. Friberg, G. F. Nordberg, and P. R. Sager (eds). Rochester Series on Environmental Toxicity. Plenum Press, NY.

Dillon H. K. and M. H. Ho (1991). Biological Monitoring of Exposure to Chemicals Metals. John Wiley \& Sons, NY.

Elinder, C. G. (1991). Biological monitoring of cadmium, in: Biological Monitoring of Exposure to Chemicals - Metals, Dillon, H. K. and M. H. Ho (eds.) J. Wiley \& Sons, NY.

Elinder, C. G. (1988). Biological monitoring of cadmium, in: Biological Monitoring of Toxic Metals, Clarkson, T.W., L. Friberg, G. F. Nordberg, and P. R. Sager (eds). Rochester Series on Environmental Toxicity. Plenum Press, NY.

Elinder, C. G., L. Gerhardsson and G. Oberdoerstger (1988). Biological monitoring of toxic metals - Overview. in: Biological Monitoring of Toxic Metals, Clarkson, T. W., L. Friberg, G. F. Nordberg, and P. R. Sager (eds). Rochester series on Environmental Toxicity. Plenum Press, NY.

Fan, A. M. and L. W. Chang (1991). Human exposure and biological monitoring of meihylmercury and selenium, in: Biological Monitoring of Exposure to Chemicals Metals, Dillon, H. K. and M. H. Ho (eds.) J. Wiley \& Sons, NY.

Fishbein, L. (1987). Perspectives of analysis of carcinogenic and mutagenic metals in biological samples. Intern. J. Environ. Anal .Chem. Vol. 28, 99 21-69. 
Friberg, L. (1988). Quality assurance, in: Biological Monitoring of Toxic Meta/s, Clarkson, T.W., L. Friberg, G. F. Nordberg, and P. R. Sager (eds). Rochester Series on Environmental Toxicity. Plenum Press, N.Y.

Hewitt, P. J. and J. T. Sanderson (1993). The role of occupational hygiene in exposure assessment by biological indices. A position paper from the Occupational Hygiene Committee of the International Congress on Occupational Health. Ann. Occup. Hyg. Vol. 37(5) 579-581.

Gompertrz, D. (1993) Editorial. The role of the hygienist in biological monitoring. Ann. Occup. Hyg. Vol. 37(5) 579-581.

Hogberg, J. and J. Alexander, (1986). Selenium, in: Handbook on the Toxicology of Metals, 2nd edition. Friberg, L ., G. F. Nordberg and V. Vouk (eds.), Elsevier Science Publishing Company.

IARC. International Agency for Research on Cancer(1986). Environmental Carcinogen Selected Methods of Analysis. Volume 8 - Some Metals. J. K. O'Neal, P. Schuller and L. Fishbein (eds). International Agency for Research on Cancer, Lyon, France.

Kazantzis, T. G (1988). The use of blood in the biological monitoring of toxic metals, in: Biological Monitoring of Toxic Metals, Clarkson, T. W., L. Friberg, G. F. Nordberg, and P. R. Sager (eds). Rochester Series on Environmental Toxicity. Plenum Press, NY.

Koirtyohann, S. R., and J. S. Morris (1986). General review of analytical method, in: Environmental Carcinogen Selected Methods of Analysis. Volume 8 - Some Metals.

J. K. O'Neal, P. Schuller \& L. Fishbein (eds). International Agency for Research on Cancer, Lyon, France.

Lowry, L. (1994). Special considerations for biological samples, in: NIOSH Manual of Analytical Methods, Cincinnati, $\mathrm{OH}$.

Magos, L. and G. G. Berg (1988). Selenium, in: Biological Monitoring of Toxic Metals, Clarkson, T. W., L. Friberg, G. F. Nordberg, and P. R. Sager (eds). Rochester Series on Environmental Toxicity. Plenum Press, NY.

Mayo Medical Laborotories. 1995 Test Catalog. Rochester, MN.

Matusiewicz, H. (1991). Analysis of micro amounts of biological naterials by inductively coupled plasma and microwave-induced plasma spectrometry with thermal vaporization: A review, in: Biological Monitoring of Exposure to Chemicals - Metals, Dillon, H. K. and M. H. Ho (eds.) J. Wiley \& Sons, NY. 
Fowler, B. A. (1988) Mechanisms of indium, thallium, and arsine gas toxicity relationships to biological indicators of cell injury, in: Biological Monitoring of Toxic Metals, Clarkson, T. W., L. Friberg, G. F. Nordberg, and P. R. Sager (eds). Rochester Series on Environmental Toxicity. Plenum Press, NY.

Hensyl, W. R. (Ed). (1990). Stedman's Medical Dictionary, 25th Edition. Williams and Wilkins, Baltimore, Md.

Nackowski, S. (1989). Analytical techniques for the determination of selenium/tellurium in blood and urine, in: Proceedings, 4th International Symposium on industrial uses of Se and Te, Banff, Canada (Selenium Tellurium Development Association).

Patel, A., 1994. Personal communication, Xerox Corporation, Webster, NY.

Smith D. L. and M. L. Bolyard (1994). Quality assurance, in: NIOSH Manual of Analytical Methods, Cincinnati, $\mathrm{OH}$.

Stoeppler, M. (1988). Analytical methods and quality control for trace metal determinations. A critical review of the State of the art, in: Biological Monitoring of Toxic Metals, Clarkson, T. W., L. Friberg, G. F. Nordberg, and P. R. Sager (eds). Rochester series on Environmental Toxicity. Plenum Press, NY.

Weber, J. P. (1994). Personal Communication, October 17, 1994. Le Centre de toxicologie du Quebec.

Suzuki T. (1988). Hair and Nails: Advantages and Pitfalls when used in biological monitoring, in: Biological Monitoring of Toxic Metals, Clarkson, T. W., L. Friberg, G, F. Nordberg, and P. R. Sager (eds). Rochester Series on Environmental Toxicity.

Plenum Press, NY.

Vaillancourt, C. R. Jean-Paul (1994). Medical surveilance of workers exposed to selenium. Presented at the Selenium-Tellurium Manufacturer's Association. May 1994.

WHO (1987). Environmental Health Criteria 58 - Selenium, World Health Organization, Geneva.

WHO (1993) Environmental Health Criteria 155. Biomarkers and Risk Assessment: Concepts and Principles, World Health Organization, Geneva.

Woodard, E. (1994). Personal communication, July 1994. Xerox Corporation, Webster, NY. 


\section{Appendix A - Occupationa1 Blomonitoring Procedures}

\begin{tabular}{|c|c|c|c|c|c|}
\hline \multirow[t]{2}{*}{ Exposure } & \multicolumn{5}{|c|}{ Measured parameters } \\
\hline & $\begin{array}{l}\text { American Conference of } \\
\text { Governmental Industrial } \\
\text { Hygienists (ACGIH, 1994) }\end{array}$ & $\begin{array}{l}\text { Deutsche } \\
\text { Forschungsgermeinschaft } \\
\text { (DFG, 1992) }\end{array}$ & $\begin{array}{l}\text { Finnish Institute of Occup } \\
\text { Health (FIOH, 1993) }\end{array}$ & pational & $\begin{array}{l}\text { United Kingdom Health and Salety } \\
\text { Excecutive (UK HSE, 1991) }\end{array}$ \\
\hline $\begin{array}{l}\text { Acetylcholinesterase } \\
\text { inhibitors }\end{array}$ & $\begin{array}{l}\text { E-acetylcholinesterase activity in } \\
\text { blood }\end{array}$ & E-acetylcholinesterase & E-acetylcholinesterase & $!$ & E-acetylcholinesterase, P-cholinesterase \\
\hline Acetone & acetone & & & & \\
\hline Aluminum (AI) & & $U-A \mid$ & U-AI & & \\
\hline Aniline & U-p-aminophenol, B-met-Hb & U-aniline & U-p-aminophenol & & \\
\hline Arsenic (As) & $\mathrm{U}$-arsenic metabolites & $\begin{array}{l}\text { U-certain volatile arsenlc } \\
\text { compounds produced by } \\
\text { direct hydrogenation }\end{array}$ & UAs $s^{\prime \prime+}, A s^{v+}$ & & UAs ${ }^{11+*}, A s^{V+}, M M A+D M A$ \\
\hline Benzene & $\begin{array}{l}\text { U-phenol } \\
\text { mixed and end-exhaled Breath- } \\
\text { benzene }\end{array}$ & B-benzene, U-phenol & B-benzene & : & Breath-, B-benzene \\
\hline p-tert-Butylphenol & & U-p-tert-butylpenol & & & \\
\hline Cadmium (Cd) & UCd, BCd & UCd, BCd & UCd, BCd & 1 & \\
\hline Carbon disulfide & $U-T T C A$ & $\mathrm{u}-\mathrm{TTCA}$ & U-TTCA & & \\
\hline Carbon monoxide & Breath-CO, B-COHb & $\mathrm{B}-\mathrm{COHb}$ & B-COHb & & $\mathrm{B}-\mathrm{COHb}$ \\
\hline
\end{tabular}




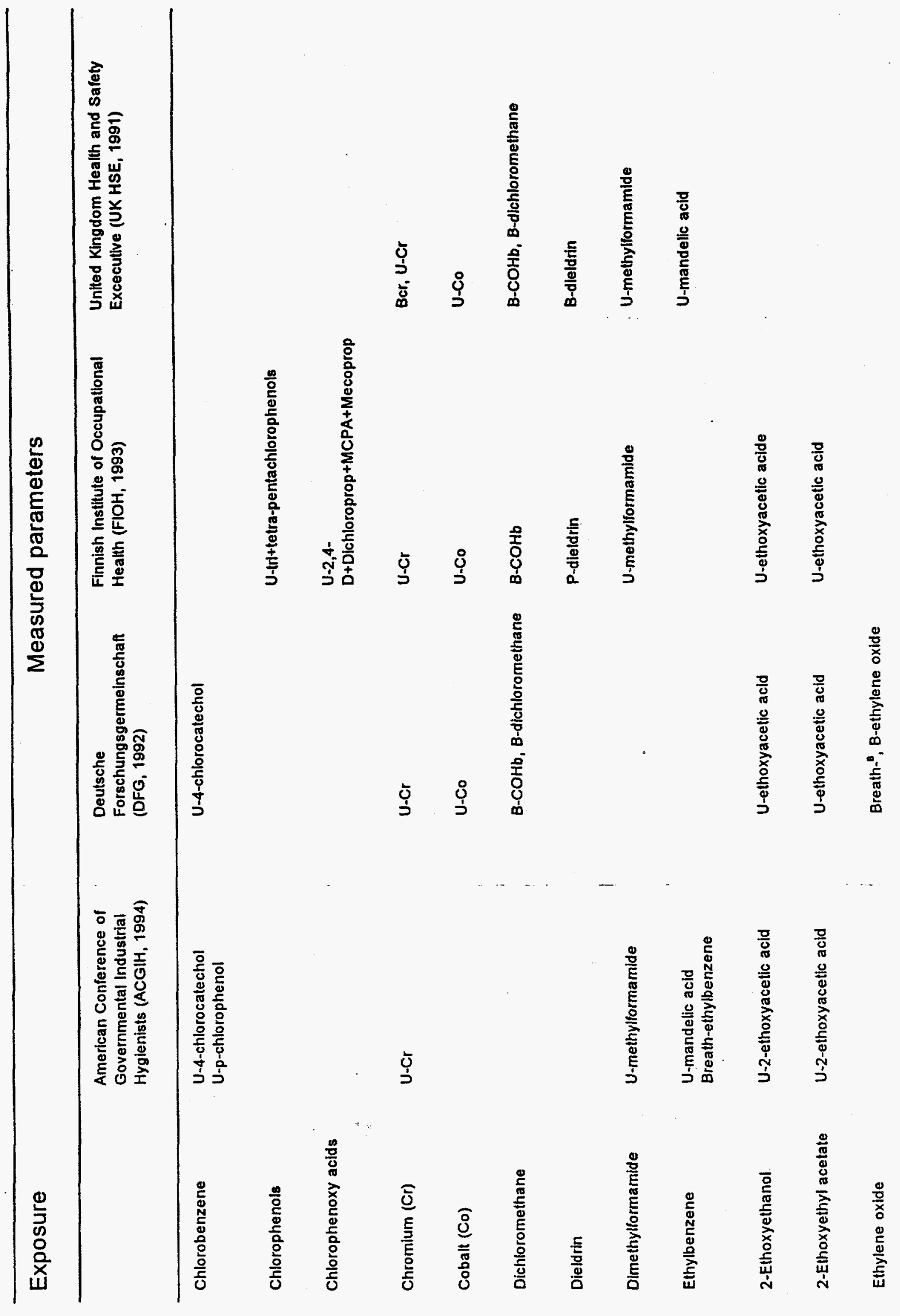




\begin{tabular}{|c|c|c|c|c|c|c|}
\hline \multirow[t]{2}{*}{ Exposure } & \multicolumn{5}{|c|}{ Measured parameters } & \multirow{2}{*}{ 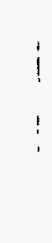 } \\
\hline & $\begin{array}{l}\text { American Conference of } \\
\text { Governmental Industrial } \\
\text { Hygienists }(A C G \mid H, 1994)\end{array}$ & $\begin{array}{l}\text { Deutsche } \\
\text { Forschungsgermeinschaft } \\
\text { (DFG, 1992) }\end{array}$ & $\begin{array}{l}\text { Finnish Institute of Occu } \\
\text { Health (FIOH, 1993) }\end{array}$ & upational & $\begin{array}{l}\text { United Kingdom Health and Safety } \\
\text { Excecutive (UK HSE, 1991) }\end{array}$ & \\
\hline Fluoride (F) & U-F & U-F & U-F & & U-F & 1 \\
\hline Furfural & U-furoic acid & & & 1 & U-furoic acid & \\
\hline Halathane & & U-trifluoroacetic acid & & : & & 1 \\
\hline Hexachlorobenzene & & P/S-hexachlorobenzene & & $\vdots$ & & i \\
\hline n-hexane & U-hexanedione, Breath-n-hexane ${ }^{c}$ & $\begin{array}{l}\text { U-hexanedione + } \\
\text { dihydroxyhezanone }\end{array}$ & U-hexanedione & i & & 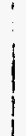 \\
\hline Hydrazine & & P-, U-hydrazine & & 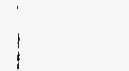 & & , \\
\hline Lead $(P b)$ & B-Pb, U-Pb, B-ZPP & $B-P b, U-A L A$ & $\mathrm{~B}-\mathrm{Pb}, \mathrm{B}-\mathrm{ZPP}$ & & B-Pb, U-ALA, B-ZPP & \\
\hline Lindane & & $B(P, S)$-lindane & B-lindane & 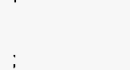 & B-lindane & \\
\hline Manganese(Mn) & & & U-Mn & & B-, U-Mn & \\
\hline Mercury $(\mathrm{Hg})$ & B-, U-Hg & $B-, U-H_{D}$ & B-, U-Hg & $i$ & B., U-Hg & \\
\hline Methanol & U-methanol, U-formate & U-methanol & U-formate & 1 & & \\
\hline Methylbromide & & & & $\vdots$ & B-Br & \\
\hline
\end{tabular}




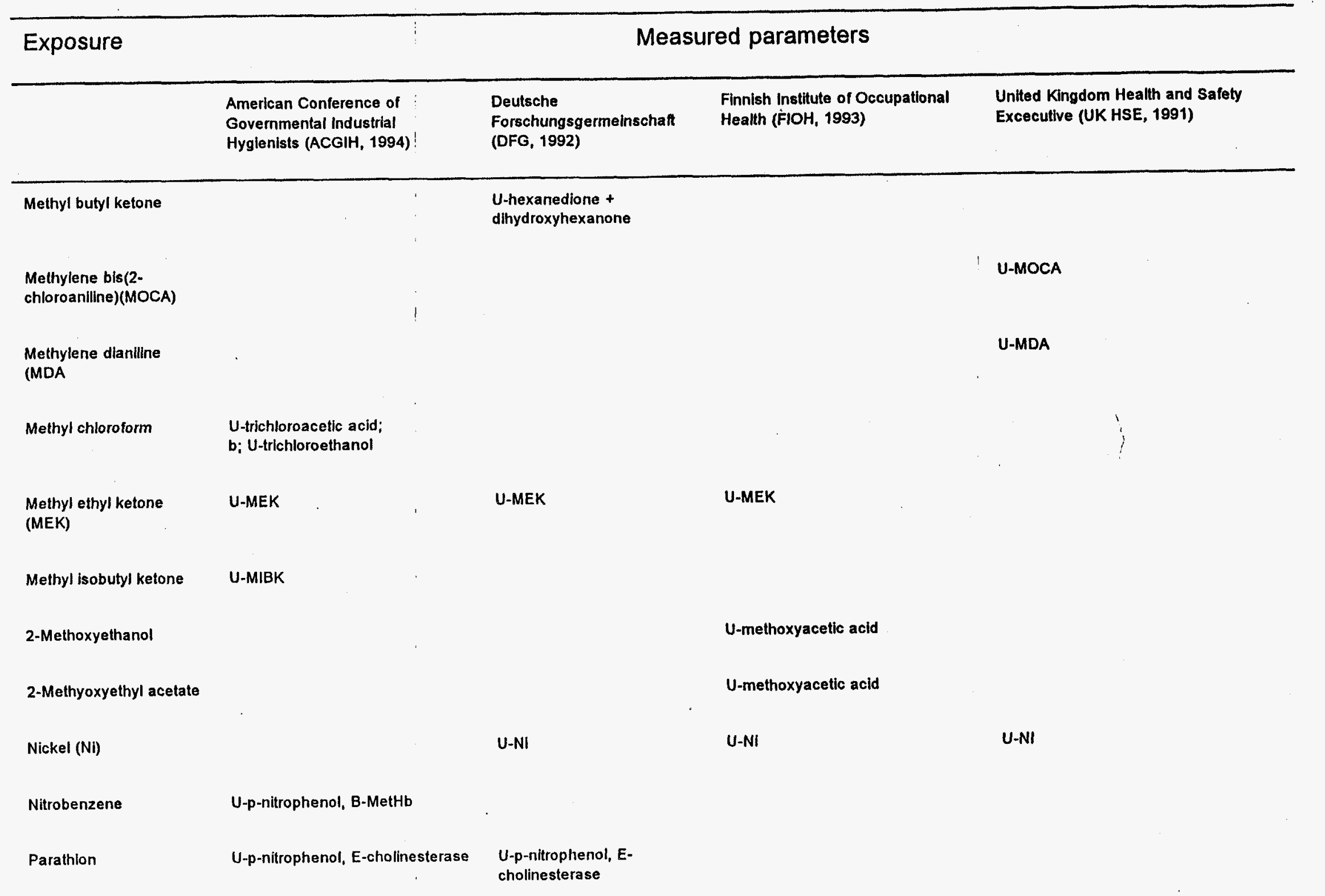




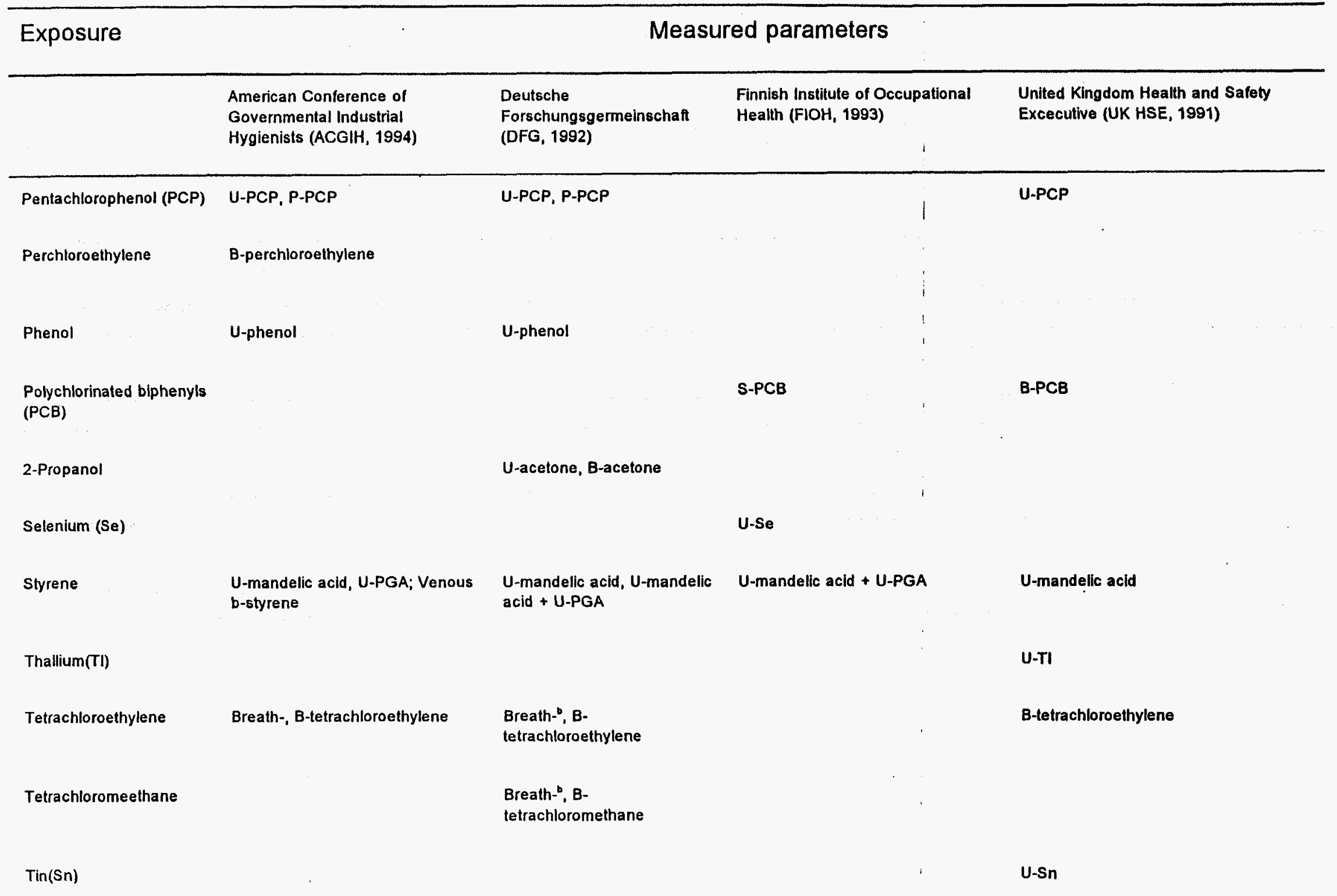




\begin{tabular}{|c|c|c|c|c|}
\hline \multirow[t]{2}{*}{ Exposure } & \multicolumn{4}{|c|}{ Measured parameters } \\
\hline & $\begin{array}{l}\text { American Conference of } \\
\text { Governmental Industrial } \\
\text { Hyglenists (ACGIH, 1994) }\end{array}$ & $\begin{array}{l}\text { Deutsche } \\
\text { Forschungsgermeinschant } \\
\text { (DFG, 1992) }\end{array}$ & $\begin{array}{l}\text { Finnish Institute of Occupational } \\
\text { Health (FIOH, 1993) }\end{array}$ & $\begin{array}{l}\text { United Kingdom Health and Safety } \\
\text { Excecutive (UK HSE, 1991) }\end{array}$ \\
\hline Toluene & $\begin{array}{l}\text { U-hippuric acid } \\
\text { B-toluene;end breath-toluene }\end{array}$ & B-toluene & B-toluene & B-toluene \\
\hline & 1 & & & \\
\hline 1,1,1-Trichloroethane & $\begin{array}{l}\text { Breath-1,1,1-trichloroethane, B- } \\
\text { trichloroethanol }\end{array}$ & $\begin{array}{l}\text { Breath-6, B-1,1,1,- } \\
\text { trichloroethane }\end{array}$ & B-1,1,1-trichloroethane & b-1,1,1-trichloroethane \\
\hline Trichloroethylene & $\begin{array}{l}\text { U-TCA, B-trichloroethanol, U- } \\
\text { TCA+trichloroethanol;breath- } \\
\text { trichloroethylene }\end{array}$ & U-TCA, B-trichloroethanol & U-TCA, U-trichloroethanol & U-TCA \\
\hline Vanadium (V) & & & U-V & U.V \\
\hline Vinyl chloride & 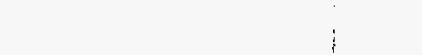 & U-thiodiglycolic acid & & \\
\hline Xylenes & U-methylhippuric acids & U-methylhippuric aclds, B- & $\begin{array}{l}\text { U-methylhippuric acids U- } \\
\text { methylhippuric acids }\end{array}$ & U-methylhippuric acids \\
\hline
\end{tabular}

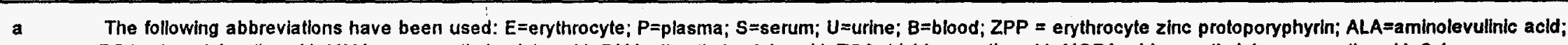

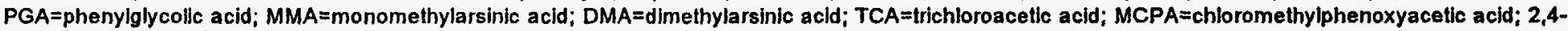
$D=2,4$ dichlorophenoxyacetic acid; TTCA=4-thiazolidine carboxylic acid.

b DFG(1992) refers to alveolar air

C ACGIH (1994) refers to end-exhaled air :

Note: Readers must consult latest edition of references for changes and before applying the above to specific situations 


\section{Appendix B. Types of Biomarkers}

\section{HEMATOLOGICAL BIOMARKERS}

Inhibition of heme synthesis pathway

Ferrokinetic measurements, e.g. plasma disappearance half-time, erythrocyte iron turnover rate

\section{NEPHROTOXICITY BIOMARKERS}

\section{Functional Markers}

Urinary proteins of low or high molecular weight

Cytotoxicity markers

Enzymes in urine

biochemical markers

\section{Liver Toxicity}

e.g. ferrochelatase, levulinate dehydratase, free erythrocyte protoporphyrin (FEB) and delta- aminolevulinate in urine used for lead

\section{Biomarker of myelotoxicity}

Serum creatinine and b2-microglobulin

albumin tranferrin, retinol-binding globulin rheumatoid factor immunoglobulin $\mathrm{G}$

Tubular antigens, e.g., beta-BB50, BBA, HF5

n-acetylglucosaminidase, B-galactosidase

eicosonoids, e.g., 6-keto PGF2 $\alpha$, PGE2, GFF2 $\alpha$ and TXB2, fibronectin, kalikrein activity, sialic acid and glycosaminoglycans in urine and red blood cell negative charges).

Biomarkers are well validated for exposure to cadmium.

Aminotransferase activites ( most often asparatate or alaninaminotransferase) in the serum. Found when the liver cells are damaged and their contents have leaked. 
Others

\section{Appendix B. Types of Biomarkers}

5-nucleotidase,alcohol dehydrogenase, lactate dehydrogenase, isocitrate dehydrogenase, leucine aminopeptidase, glutathione S-transferase, ornithine carbamoyl transferase

Serum levels may be elevated not only after liver damage but also when nonhepatic tissues have been damaged because other tissues contain these enzymes.

To overcome this lack of specificity, specific isoenzymes are used. Serum activities of enzymes such as alkyline phosphatase and $\gamma$-glutamyl transpepidase are used as biomakers of hepatic damage of biliary excretion.

Concentrations of serum proteins synthesized in the liver, e.g., albumin and clotting factors or serum concentrations of bile acids (also synthesized in the liver)

Tests for hepatic excretory function, such as half-life of bromsufphthalein.

Note: Hepatic viral infections, alcohol and drug use also effect these enzyymes.

e.g. carbon tetrachloride is metabolized to a reactive intermediate which depletes intracellular glutathione; if sufficiently depleted the intermediate will react with critial macromolecules and cause cell death and hepatotocity. Therefore biomarkers include glutathione levels, lipid peroxidation, or the number of necrotic cells.
Hepatotoxicity is caused by many chemicals metabolized by the cytochrome P-450-dependent mixed-function oxidase system to reactive intermediates. When the metabolite reacts with critical macromolecules it leads to cell death and hepatotoxicity.

\section{Biomarkers of immunotoxicity}




\section{Appendix B. Types of Biomarkers}

Hypersensitivity reactions

Inhalation reactions

Asthma, rhinitis, pheumonitis, granulomatous pulmonary reactions

Dermal reactions

Patch tests used for diagnostic measurements. Note: hypersensityivity can be induced by the patch test itself.

Elevated levels of antibodies, e.d. IgE may. Not all persons with high IgE are sensitive

indicate sensitization.

Not all sensitive people have high levels of IgE

Immune suppression

Increases risk of infections and neoplasia.

Changes in ratios and abundance of different lymphocyte subpopulations can be used as biomarkers for immune suppression (e.g., suppressor and helper T. cells)

\section{Pulmonary Toxicity}

Peak expiratory flow, forced expiratory volume, transfer factors

Measures of gross effects on pulmonary function, rather than effects on cells or biochemical processes

ANALYSIS OF BRONCHOALVEOLAR LAVAGE FLUID (BALF) detects lung injury or follows the progress of pulmonary disease or the efficacy of therapeutic treatment. Recently used to define dose-response characteristics of inhaled or instilled toxins in animal toxicity studies.

Types of BALF indicators

High percentage of lymphocytes -

indicative of granulomatous procecesses,e.g. sarcoidosis, or hypersensitivity pneumonitis 


\section{Appendix B. Types of Blomarkers}

High percentages of neutrophils - (with some eosinophils -

Protein level and extracellular enzymatic material

\section{Lactate dehydrogenase (LDH) -}

Beta-glucuronidase (or other lysosomal $\tilde{\sigma}$ hydrolytic enzyme) -

Cytokine secretion from pulmonary macrophages

Tumor necrosis factor (TNF) released by macrophages

\section{Glutathione (GSH)}

Nasal lavage fluid (NLF) -

Blood biomarkers for lung injuries have not been validated. indicative of idiopathic pulmonary fibrosis

- the most sensitive biomarker of an inflammatory response in the bronchoalveolar region is the number of neutrophils in BALF.

Increased protein material indicates increased permeability of the alveolar/capillary barrier

cytoplasmic enzyme found extracellularly only in the presence of lysed or damaged cells.

excellent marker for the toxicity of inhaled particles. Particles are phagocytosed by macrophages; the enzymes are released when the macrophages are activated or lysed.

obtained by bronchoalveolar lavage; markers of fibrotic development.

associated with quartz-induced fibrotic disease.

a tripeptide, protective against oxidative stress. Found in BALF. Decrease GSH is a potential marker for oxidative stress, and has been found in patients with idiopathic pulmonary fibrosis

marker for inhaled toxins, e.g., influx of neutrophils into the human nasal cavity in response to inhaled ozone. 


\section{Appendix B. Types of Biomarkers}

Urinary levels of amino acids associated

e.g., hydroxyproline, hydroxylysine, desmosine and isodesmosine. with connective tissue of the lung have been used as markers of lung injury. However these are not specific for lung injury but indicate breakdown of connective tissue in any organ in the body.

\section{BIOMARKERS OF REPRODUCTIVE AND DEVELOPMENTAL TOXICITY}

Male reproducive system

Physiological indicators of impaired

testicular function, sperm number, or characteristics

Hormonal status measured in blood

e.g., FSH, LH, and testosterone.

Hormonal status measured in urine and saliva

e.g., testosterone.

Better picture of hormonal status can be obtained by administering GnRH or LH and examining hormonal response to challenge.

\section{Female reproductive system}

No well developed biomarkers for female reproductive system. 


\section{Appendix B. Types of Biomarkers}

\section{Developmental Toxicity}

Proposed biomarkers for pregnancy, e.g. early pregnancy loss and assays for genetic defects of the conceptus.

Urinary human chorionic gonadotrophin (HCG)

\section{BIOMARKERS OF NEUROTOXICITY}

Exposure to organophosphorus compound and cholinesterase inhibiters,

\section{Electroneuromyography}

Neurobehavioral and neurophysiological tests

Chemical induced changes in the brain
Low birth weight

chromosome abnormalities

delayed growth of specific organ systems,

mental retardation

subtle behavior changes

Many other biomarkers are available, but have not been used to study effects of chemicals on pregnancy.

biomarker for early fetal loss

e.g., inhibition of plasma and erythrocyte acetylcholine esterase (AChE) (Note: plasma pseudocholinesterase only reflects exposure and is not a marker of CNS effects).

Measure of peripheral nervous system dysfunction due to chemical exposure; this can be done at a preclinical stage.

Used to evaluate CNS dysfunction induced by neruotoxicants if performed under controlled conditions.

Computed axial tomography (CAT)

Magnetic resonance imaging (MRI) 


\section{Appendix B. Types of Biomarkers}

Biochemical status of central nervous system, metabolism

Analysis of chemicals and metabolites

\section{BIOMARKERS FOR GENOTOXIC CARCINOGENS}

\section{BIOMARKERS OF SUSCEPTIBILITY}

Predominantly genetic in origin

May vary between ethnic groups

\section{Genetic}

Sickle cell phenotype

$\lg A$ deficiency phenyl ketones in urine

Acetylator phenotype

Ataxia telangiectasia genotype
Nuclear magnetic resonance spectroscopy (NMRS), positron-emission tomography (PET) measures rate of energy generation, blood flow, L-glucose metabolism

disadvantage; Expensive; Little use of assessing changes in spinal cord, nerve, and muscle.

Urinary or blood concentrations of chemicals have been used as biomarkers

DNA adducts, protein adducts, cytogenetic methods, chromosome damage, sister chromatid exchange,

Identifies factors that may change an individual's risk of developing a toxic response following exposure to an environmental agent.

More sensitive to aromatic amino and nitro compounds, carbon monoxide, cyanide, lead, and benzene. Produces anemia

More susceptible to precursors of phenyl ketones - produce irritation of respiratory tract and phenylketonuria

Exposure to aflotoxin may cause liver cancer; aromatic amines induce bladder cancer

Exposure to bleomycins, produces cancer at various sites. 


\section{Appendix - C \\ Selection of Sampling Methodologies}

NIOSH (Lowry 1994) specified areas that should be identified when selecting biological monitoring methodologies. Selection process should involve the occupational health professional familiar with the workplace, a competent laboratory chemist, and a physician knowledgeable in occupational medicine. The following areas should be addressed:

(1) Does the survey require rapid, semi-quantitative (non-specific) or specific methodologies?

(2) Does the diet, drugs, alcohol, disease states or other workplace chemicals interfere with the method? If so, can these interferences be controlled?

(3) Does the sample matrix affect the analysis? In general, blood serum and urine specimens require different methods of preparation and may require separate methodologies to eliminate matrix effects.

(4) Is the limit of detection low enough to differentiate exposed from non-exposed workers? The method may have been developed when exposure limits were higher.

(5) Does the method have guidelines for interpretation of the data or are published guidelines/normals available? If not, can non-exposed workers be used for controls or reference baseline data?

b. Sampling Strategy.

Strict attention to sample integrity is essential for quality data. The ideal "perfect" laboratory method and trained analyst cannot produce good results unless:

(1) the correct specimen is collected;

(2) the specimen is collected at the right time after exposure to the toxic substance; 
Appendix $\mathrm{C}$ continued

(3) the proper container, with preservative or anticoagulant, is used;

(4) the field specimen is properly prepared;

(5) the specimen is not contaminated;

(6) the stability of the analyte is assured through proper shipment of the specimen to the laboratory; and

(7) the specimen is properly labeled. 
Analyses for trace metals at Mayo Clinic and Mayo Medical Laboratories are performed in an ultra-clean laboratory environment using a system of positive-pressure filtered air to prevent specimen contamination due to dust. This allows for detection of many metals at the sub-part-per-billion concentration range. Contamination control must be practiced during sample collection to provide a specimen that will yield clinically useful results. We recommend and strongly urge the use of a specific set of blood collection tubes for specimen collection and that phlebotomists carry out the proven techniques described below.

The Metals Laboratory at Mayo Clinic has tested numerous blood collection tubes and has found most of them to introduce contamination when used for trace metal specimen collection. Standard red-topped evacuated clot tubes and all plastic syringes with black rubber seals are grossly contaminated with zinc, and all contain varying amounts of heavy metals (lead, mercury, cadmium, nickel, chromium, and others). All rubber stoppers (except the one used on the tube recommended below) have significant concentrations of aluminum in the rubber that is carried into the sample on the puncturing needle, contaminating the sample. Most evacuated tubes for plasma or whole blood collection that are not specifically designed for trace metal specimen collection contain anticoagulants contaminated with trace metals. These problems have been noted in numerous publications. ${ }^{1-5}$

We require the use of EDTA as an anticoagulant for whole blood samples. Other anticoagulants (heparin, for example) are effective only for 24-36 hours. Frequently, transportation time to Rochester exceeds this time; heparinized specimens frequently arrive partially clotted, making analysis and interpretation of results difficult.

When multiple blood samples are scheduled for collection from one patient, the trace metal specimens should be collected first; once the phlebotomy needle has punctured another rubber stopper, it is contaminated and should not be used for trace metal specimen collection.

Always use an alcohol swab to cleanse the venipuncture site. Avoid iodine-containing disinfectants. Use only stainless steel phlebotomy needles.

Blood specimens for serum testing should be collected in the Monoject $\otimes$ Trace Element.Blood Collection Tube, product number 8881-307006. Allow the specimen to clot for 30 minutes; then centrifuge the specimen to separate serum from the cellular fraction. Remove the stopper and carefully pour the serum into a $5 \mathrm{cc}$ Mayo metal-free screw-capped polypropylene vial, avoiding transfer of the cellular components of blood. DO NOT insert a pipet into the serum to accomplish transfer, and DO NOT ream the sample with a wooden stick to assist with serum transfer. Place the cap on the polypropylene vial tightly, attach a specimen label, and send specimen to the laboratory at refrigerated or frozen temperature.

A specimen for whole blood testing should be collected in a Monoject $\circledast$ Trace Element Blood Collection Tube, product number 8881-307022, containing EDTA as an anticoagulant. Leave the specimen in the tube, attach an identification label, and send the specimen to the laboratory at cool temperature. Alternatively, pediatric specimens can be drawn in a BectonDickinson Microtainer ${ }^{\circledR}$, product number 5973, with EDTA anticoagulant. An absolute volume of $500 \mu \mathrm{L}$ is required for testing for each analyte ordered.

In the unlikely event that Monoject Trace Metal Blood Collection Tubes cannot be used, Mayo has available a specially prepared polypropylene syringe that will not contaminate the specimen. The Mayo metal-free syringe is used as follows:

\section{Serum}

1. Perform venipuncture using a stainless steel needle. A 20-gauge needle (Becton-Dickinson \#5175 or equivalent) or Terumo or Abbott butterfly blood collection device can also be used.

2. Attach a blue-labeled Mayo metal-free syringe and slowly draw a volume of blood to fill it. Withdraw the needle from the vein and discard. Cap the syringe and unscrew and discard the plunger.

3. After 30 minutes to allow for clotting, centrifuge the specimen in the syringe (up to $3,000 \mathrm{rpm}$ is acceptable).

4. After centrifugation, pour the serum into the blue-labeled $5 \mathrm{cc}$ Mayo metal-free screw-capped polypropylene vial. DO NOT transfer the specimen with a pipette. A $3.0-\mathrm{mL}$ sample volume is adequate for multiple requests.

5. Place the screw-top cap firmly on the vial, attach an identification label, and send to laboratory at refrigerated temperature. All specimens to be stored more than 48 hours should be frozen and sent on dry ice. 


\section{Whole Blood}

1. Insert needle attached to the EDTA Mayo metal-free (yellow label) syringe containing anticoagulant into the venipuncture site and withdraw blood to fill the syringe. Remove the needle from the vein and discard.

2. Cap the syringe and unscrew the plunger (discard). Invert syringe several times to mix blood and anticoagulant.

3. Transport the syringe to the laboratory at refrigerated temperature. Specimens to be stored more than 48 hours show be stored at $4^{\circ} \mathrm{C}$ and sent refrigerated (keep specimen cool with frozen coolant April-October, refrigerated coolan: November-March).

\section{Urine}

We have not found it necessary to provide acid-washed containers for urine collection. We urge the use of acid-washt. plastic containers for specimen collection and transport.

Acid stabilized specimen collection is essential for accurate analysis of calcium, magnesium, and oxalate. If the urine $\mathrm{p}$ : is $>4$, some of these elements will be lost in the urine sediment such that at the time of aliquot separation, some of the sediment will be unhomogeneously divided.

DO NOT collect urine specimens in the environment in which exposure is most likely to occur. It is important that dus: from clothing not contribute to the specimen contents.

DO NOT collect urine in metal-based containers such as metal urinals or pans.

\section{Tips to Control Contamination}

1. Keep patient specimen area clean and free of dust.

2. It is best to use the Monoject $(8$ evacuated blood tube or the Mayo metal-free syringes, vials, and needles.

3. DO NOT touch specimen with utensils unless they have been acid-washed.

4. Dialysis patients on heparin may form an uncoagulated serum when centrifuging. Pour off serum as soon as possible invert the clot tube, and repeat centrifugation step to separate cellular fraction if more serum is needed.

5. DO NOT leave serum on cells more than 60 minutes. Centrifuge and pour serum into metal-free vial.

\section{References}

'Moody JR, Lindstrom RM: Selection and cleaning of plastic containers for storage of trace element samples. Anal Chem: 49:2264-2267, 1977

${ }^{2}$ Lecomte R, Paradis P, Monar S, et al: Trace element contamination in blood-collecting devices. Int J Nucl Med Biol 6:20; 211,1979

${ }^{3}$ Handy RW: Zn contamination in vacutainer tubes. Clin Chem 25:197-198, 1979

${ }^{4}$ Ericson SP, MCHalsky ML, Rabinow BE, et al: Sampling and analysis techniques for monitoring serum for trace elements. Clin Chem 32:1350-1356, 1986

${ }^{5}$ Nixon DE, Moyer TP, Squillace DP, McCarthy TT: Determination of serum nickel by graphite furnace atomic absorption spectrometry with Zeeman-effect background correction: values in a normal population and a population undergoing dialysis. Analyst 114:1671-1674, 1989 
Appendix E. Reference Values for Adducts in Urine

\begin{tabular}{ll}
\hline & Mean (range) \\
\hline Volume (I/day) & $1.2(0.6-2.5)$ \\
Solid (g/day) & $50(30-70)$ \\
Specific gravity & 1.020 \\
Creatine (g/day) & $1.0-1.6$ \\
Creatinine (g/L) & $1.0(0.3-3.4)$ \\
$\mathrm{pH}$ & $6.094 .6-8.0)$ \\
\hline
\end{tabular}

ACGIH (1994). Sources of variability in biological exposure monitoring, in: Documentation of the Biological Exposure Indices, Cincinnati, $\mathrm{OH}$. 


\section{NIOSH Manual of Analytical Methods}

Compiled by NIOSH. All rights reserved (1994). Protected under International Copyright, U.S. Department of Health and Human Services. Provided by CCOHS.

METALs in urine

MTHOD: 8310

FORMOLA: Table 1

M.W.: Table 1

ISSUED: $2 / 15 / 84$

BIOLOGICAL INDICATOR OF:

exposure to the following metals or their compounds: aluminum, barium, cadmium, chromium, copper, iron, lead, manganese, molybdenum, nickel, platinum, silver, strontium, tin, titanium, and zinc.

\section{SYNONYMS :}

vary according to the compound.

\section{BIOLOGICAI SAMPLING}

SPECIMEN : urine

VOLUME: 50 to $200 \mathrm{~mL}$ in polyethylene bottle

PRESERVATIVE: $5.0 \mathrm{~mL}$ conc. HNO3 added after collection

SHIPMENT: frozen in dry ice

STABILITY: not established

CONTROLS: collect at least 3 urine specimens from unexposed workers

\section{MEASUREMENT}

TECHNIQUE: INDUCTIVELY-COUPLED ARGON PLASMA, ATOMIC EMISSION SPECTROSCOPY

ANALYTE: elements above

EXTRACTION MEDIA: polydithiocarbamate resin

FINAI SOLUTION: $4 \frac{\circ}{8} \mathrm{HNO}_{3}, 1 \% \mathrm{HClO}_{4} ; 5 \mathrm{~mL}$

WAVELENGTH: depends upon element; Table 1

BACKGROUND CORRECTION: spectral wavelength shift

CALIBRATION: elements in $4 \frac{\circ}{\circ} \mathrm{HNO}_{3}, 1 \% \mathrm{HClO} 4$ 
QUALITY CONTROL: spiked urines; corrected for creatinine

RANGE: 0.25 to $200 \mathrm{\mu g}$ per sample [1]

ESTIMATED LOD: $0.1 \mu \mathrm{g}$ per sample

PRECISION $(s x):$ Table 1

\section{APPLICABILITY:}

This method measures urine concentrations of metals. It is particularly useful for workers exposed to several metals simultaneously. This is a simultaneous, multielemental analysis, but is not compound specific.

\section{INTEREERENCES :}

Spectral interferences are the primary interferences encountered in ICP-AES analysis. These are minimized by judicious wavelength selection and interelement correction factors. Background corrections are also made $[1,2]$.

OTHER METHODS:

This is a new method which uses a measurement technique similar to that of Method 7300 for air samples.

PROCEDURE

REAGENTS:

1. Polydithiocarbamate resin, prepared as described in the APPENDIX.

2. Nitric acid, conc.*

3. Perchloric acid, conc.*

4. Dissolution acid, $4: 1$ (v/v) $\mathrm{HNO}_{3}: \mathrm{HClO}_{4}$. Mix 4 volumes conc. $\mathrm{HNO}_{3}$ with 1 volume conc. $\mathrm{HClO}_{4}$.*

5. Metals standards, $1000 \mu \mathrm{g} / \mathrm{mL}$. Commercially available or prepared per instrument manufacturer's recommendations.

6. Argon.

7. Deionized water.

8. Sodium hydroxide, $5 \mathrm{M}$. Dissolve $20 \mathrm{~g} \mathrm{NaOH}$ in $50 \mathrm{~mL}$ boiled, deionized water; dilute to $100 \mathrm{~mL}$. Store in a polyethylene bottle.

*See Special Precautions. 
1. Bottles, polyethylene, 125 - or 250-mL, plastic-lined screw-cap.*

2. Inductively-coupled plasma-atomic emission spectrometer equipped for determination of elements of interest.

3. Regulator, two-stage, for argon.

4. Filtering apparatus for $50 \mathrm{~mL}$ liquid with $47-\mathrm{mm}$ cellulose ester, $0.8-\mu \mathrm{m}$ pore size filters.

5. Beakers, Griffin, 50-mL, with watchglass covers.*

6. $\mathrm{pH}$ meter and electrodes.

7. Volumetric flasks, 5- and 100-mL,*

8. Assorted volumetric pipets as needed.*

9. Hotplate, suitable for use at $100^{\circ} \mathrm{C}$.

10. Mechanical shaker.

11. Low temperature oxygen plasma asher (acid ashing may be substituted; see APPENDIX).

* Clean all labware with detergent, soak $12 \mathrm{hrs}$ in $10 \%(\mathrm{v} / \mathrm{v})$ HNO3, and soak 12 hrs in deionized water.

SPECIAI PRECAUTIONS:

Concentrated acids are extremely corrosive. Work with concentrated acids only in fume hoods and wear appropriate safety equipment (safety glasses or face shield, gloves, and labcoat).

\section{SAMPLING:}

1. Collect a 50-mI urine sample in a polyethylene bottle.

2. Add $5 \mathrm{~mL}$ cone. $\mathrm{HNO}_{3}$ as a preservative.

3. Pack samples in an insulated shipping container under refrigeration (e.g., styrofoam with dry ice) for transportation to laboratory.

\section{SAMPLE PREPARATION :}

4. Perform a creatinine determination on an aliquot of the sample $(\mathrm{e} . \mathrm{g} .,[5])$.

5. Adjust the sample $\mathrm{pH}$ to $2.0 \pm 0.1$ with $5 \mathrm{M} \mathrm{NaOH}$ and then add $60 \pm$ $10 \mathrm{mg}$ polydithiocarbamate resin. 
- NOTE: Start reagent blanks, in triplicate, at this step. Include resin and filters (step 7 ).

6. Agitate samples (on the shaker) for at least 12 hrs.

7. Filter samples through a 0.8-um cellulose ester membrane filter, saving the filtrate and resin. Place the collected resin and filter in a clean 50-mL beaker.

8. Adjust filtrate $\mathrm{pH}$ to $8.0+0.1$ with $5 \mathrm{M} \mathrm{NaOH}$, add more resin, then repeat steps 5 and 6 , combining the filters and resins from the two extractions.

9. Ash filters and resins in a low temperature oxygen plasma asher for 6 hrs or until ashing is complete $(200$ watts at 1 to 2 torr, or manufacturer's recommendations).

NOTE: Steps 5 to 10 of Method 7300 (this Manual), an HNO3/HClO4 digestion, may be substituted for the low temperature oxygen plasma ashing. Use a final solution volume of $5.0 \mathrm{~mL}$ (step 11).

10. Add $0.5 \mathrm{~mL}$ dissolution acid and warm on a hotplate (15 min at $\left.50{ }^{\circ} \mathrm{C}\right)$.

11. Transfer solutions quantitatively to $5-\mathrm{mL}$ volumetric flasks and dilute to volume with distilled deionized water.

CALIBRATION AND QUALITY CONTROL:

12. Calibrate the spectrometer according to manufacturer's recommendations.

NOTE: Typically, an acid blank and $10 \mu \mathrm{g} / \mathrm{mL}$ multielement solutions are used.

13. Analyze a standard for every 10 samples.

14. Check analytical recoveries with at least three spiked unexposed urine samples per 10 samples.

NOTE: For urine spikes, a 100-mL control urine sample is split and $50 \mathrm{~mL}$ analyzed without spiking. The metal quantity found in the unspiked portion is subtracted from the metal quantity found in the spiked portion in order to determine the measurement recovery.

MEASUREMENT :

15. Set the spectrometer to conditions specified by the manufacturer.

16. Analyze standards and samples.

NOTE: If the values for the samples are above the range of the standards, dilute the sample solutions with 1 volume dissolution acid +9 volumes deionized water, reanalyze, and apply the appropriate dilution factor in the calculations. 
17. Obtain the solution concentration for the sample, $C_{s}(\mu \mathrm{g} / \mathrm{mL})$, and the average blank, $\mathrm{Cb}(\mu \mathrm{g} / \mathrm{mL})$, from the analyses data.

18. Using the solution volumes of sample, $V_{S}(\mathrm{~mL})$, and blank, $\mathrm{Vb}(\mathrm{mL})$, calculate the concentration, $C(\mu \mathrm{g} / \mathrm{mL})$, of each element in the volume of urine collected, $\mathrm{V}(\mathrm{L})$ :

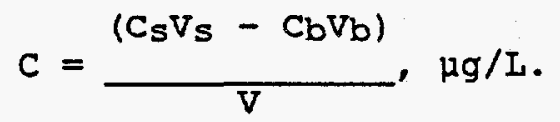

19. Report the results as $\mu$ g metal/g creatinine.

GUIDELINES TO INTERPRETATION:

Acceptable and unacceptable levels for metals have not been determined by this method. Lauwerys [6] discusses metals and can be consulted for guidance and interpretation.

EVALUATION OF METHOD:

Recovery of these 16 metals from spiked urine samples are shown in Table 1 (recoveries ranged from 77 to $100 \%$ ). The precisions determined for the various elements are also given in Table 1 [1].

\section{REFERENCES:}

[1] Hull, R. D. and D. Molina. Trace Element Analysis of Urine by Inductively Coupled Plasma-Atomic Emission Spectroscopy, NIOSH Internal Report, NIOSH, DPSE, MRB, IMDS (September, 1983).

[2] Hull, R. D. Multilement Analysis of Industrial Hygiene Samples, NIOSH Internal Report, presented at the American Industrial Hygiene Conference, Portland, OR (May, 1981).

[3] Hackett, D. S. and S. Siggia. Selective Concentration and Determination of Trace Metals Using Polydithiocarbamate Chelating Ion-Exchange Resins, Environmental Analysis, 253, (G. W. Ewing, ed.), Academic Press, NY (1977).

[4] Bray, J. T. and F. J. Reilly. Extraction of Fourteen Elements from a Sea Water Matrix by a Polydithiocarbamate Resin, Jarrell-Ash Plasma Newsletter, $\underline{4}, 4$ (1981).

[5] Tietz, N. W. Fundamentals of Clinical Chemistry, 2nd ed., 994-997, W. B. Saunders Co., Philadelphia, PA (1976).

[6] Lauwerys, R. R. Industrial Chemical Exposure: Guidelines for Biological Monitoring, Biomedical Publications, Davis, CA (1983).

METHOD WRITTEN BY: R. DeIOn Hull, NIOSH/DPSE. 
Table 1. Recovery of metals from urine $[1,2]$.

\begin{tabular}{|c|c|c|c|c|c|}
\hline $\begin{array}{l}\text { Element } \\
\text { (Formula) }\end{array}$ & $\begin{array}{l}\text { Atomic } \\
\text { Weight }\end{array}$ & $\begin{array}{l}\text { Wavelength } \\
\text { (nm) }\end{array}$ & $\begin{array}{l}\text { Metal } \\
\text { Quantity } \\
\text { Added, } \\
\mu \mathrm{g} / 50 \mathrm{~mL} \\
\text { sample }\end{array}$ & $\begin{array}{l}\text { Precision, } \\
s_{r} \\
(n=4)\end{array}$ & $\begin{array}{l}\text { Recovery } \\
\text { R }\end{array}$ \\
\hline Aluminum (Al) & 26.98 & 308.2 & 20 & 0.088 & 100 \\
\hline Barium (Ba) & 137.34 & 455.4 & 0.4 & 0.11 & 80 \\
\hline Cadmium (Cd) & 112.40 & 226.5 & 1.0 & 0.12 & 100 \\
\hline Chromium (Cr) & 52.00 & 205.6 & 1.0 & 0.078 & 100 \\
\hline Copper (Cu) & 63.54 & 324.8 & 10 & 0.042 & 100 \\
\hline Iron (Fe) & 55.85 & 259.9 & 40 & 0.059 & 100 \\
\hline Lead $(\mathrm{Pb})$ & 207.19 & 220.4 & 10 & 0.040 & 100 \\
\hline Manganese $(M n)$ & 54.94 & 257.6 & 10 & 0.50 & 85 \\
\hline Molybdenum (Mo) & 95.94 & 281.6 & 2.0 & 0.16 & 100 \\
\hline Nickel (Ni) & 58.71 & 231.6 & 2.0 & 0.42 & 80 \\
\hline Platinum $(P t)$ & 195.09 & 203.7 & 0.4 & 0.29 & 77 \\
\hline Silver (Ag) & 107.87 & 328.3 & 2.0 & 0.12 & 100 \\
\hline Strontium $\langle S r\rangle$ & 87.62 & 421.5 & 4.0 & 0.25 & 100 \\
\hline $\operatorname{Tin}\left(S_{n}\right)$ & 118.69 & 190.0 & 2.0 & 0.21 & 100 \\
\hline Titanium (Ti) & 47.90 & 334.9 & 2.0 & 0.16 & 86 \\
\hline Zine $(Z n)$ & 65.37 & 213.9 & 200 & 0.089 & 100 \\
\hline
\end{tabular}

\section{APPENDIX:}

POLYDITHIOCARBAMATE RESIN PREPARATION

The procedure used for preparation of the polydithiocarbamate resin is that of Hackett and Siggia [3] as modified by Bary and Reilly [4] .

1. Dissolve $72 \mathrm{~g}$ polyethyleneimine*, molecular weight 1800 , in $1 \mathrm{I}$ tetrahydrofuran and $28 \mathrm{~g}$ polymethylenepolyphenyl isocyanate in $1 \mathrm{I}$ tetrahydrofuran.

2. Pour these two solutions simultaneously into a large flask, allowing the two streams to $\mathrm{mix}$ before entering the flask.

3. Let this mixture stand at least 12 hrs with occasional mild agitation, then remove the solvent by filtration.

4. Wash the product twice with methanol and once with deionized water.

5. Add the product to $300 \mathrm{~mL}$ carbon disulfide, $100 \mathrm{~mL}$ ammonium hydroxide and $500 \mathrm{~mL}$ isopropyl alcohol; let stand 72 hrs.

6. Filter to remove the resin from the solvent mixture. Wash the resin three times with methanol and allow it to dry.

7. Grind and sieve the resin, saving the $60 / 80$ mesh size for use.

* Polyethyleneimine stored for one year would not dissolve in the solvent; however, fresh polyethyleneimine readily dissolved. 


\section{NIOSH Manual of Analytical Methods}

Compiled by NIOSH. All rights reserved (1994). Protected under International Copyright, U.S. Department of Health and Human Services. Provided by CCOHS.

EImMans in blood or tissue MrTaOd: 8005

FORMULA: Table 1

M.W.: Table 1

ISSUED: $\quad 5 / 15 / 85$

BIOLOGICAL INDICATOR OE:

exposure to the following elements or their compounds: antimony, cadmium, chromium, cobalt, copper, iron, lanthanum, lead, lithium, magnesium, manganese, molybdenum, nickel, platinum, silver, strontium, thallium, vanadium, zinc and zirconium.

SYNONYMS :

vary according to compound.

BIOLOGICAL SAMPLING

SPECIMEN: BLOOD OR TISSUE

VOLUME: $10 \mathrm{~mL}$ (blood) or $1 \mathrm{~g}$ (tissue)

PRESERVATIVE: heparin (blood); none for tissue

SHIPMENT: frozen for blood and "wet" tissue; routine for "dry" tissue

STABILITY: not established

CONTROIS: collect at least 3 blood specimens from unexposed workers

\section{MEASUREMENT}

METHOD: INDUCTIVELY-COUPLED ARGON PLASMA-ATOMIC EMISSION SPECTROSCOPY

ANALYTE: elements above

DIGESTION ACID: $3: 1: 1(\mathrm{v} / \mathrm{v} / \mathrm{v})$ HNO3:HClO4:H2SO4

FINAL SOLUTION: $10 \% \mathrm{H} 2 \mathrm{SO}_{4} ; 10 \mathrm{~mL}$ (blood), $5 \mathrm{~mL}$ (tissue)

WAVELENGTit: depends upon element; Table 1

BACKGROUND CORRECTION: spectral wavelength shift

CAIIBRATION: elements in $10 \% . \mathrm{H} 2 \mathrm{SO}_{4}$ or yttrium internal standard

QUALITY CONTROL: spiked blood or tissue; reference materials 
RANGE: 10 to $10,000 \mu \mathrm{g} / 100 \mathrm{~g}$ blood; 2 to $2000 \mu \mathrm{g} / \mathrm{g}$ tissue

ESTIMATED LOD: $1 \mu \mathrm{g} / 100 \mathrm{~g}$ blood; $0.2 \mu \mathrm{g} / \mathrm{g}$ tissue

PRECISION $\left(s_{r}\right)$ : Table 1

\section{APPLICABILITY:}

This method is useful for monitoring the blood of workers exposed to several metals simultaneously. This is a simultaneous multielemental analysis, but is not compound-specific.

\section{INTERFERENCES :}

Spectral interferences are sometimes encountered. These are minimized by judicious wavelength selection and interelement correction factors. Background corrections (spectral wavelength shift) are also made $[1,2]$.

\section{OTHER METHODS :}

This is a new method which uses a measurement technique similar to that of Methods 7300 (for air samples) and 8310 (for urine samples).

\section{RROCEDURE}

\section{REAGENTS :}

1. Nitric acid, conc. (high purity).*

2. Perchloric acid, conc. (high purity).*

3. Sulfuric acid, conc. (high purity).*

4. Digestion acid, $3: 1: 1(\mathrm{v} / \mathrm{V} / \mathrm{V})$ HNO3:HClO4:H2SO4.* Mix three volumes conc. $\mathrm{HNO}_{3}$ with one volume conc. $\mathrm{HClO}_{4}$ and one volume conc. $\mathrm{H}_{2} \mathrm{SO}_{4}$.

5. Element standards, $1000 \mu \mathrm{g} / \mathrm{mI}$. Commercially available or prepared per instrument manufacturer's recommendations.

6. Reference materials of known elemental composition. SRM \#1577a, Bovine Iiver, from the U.S. National Bureau of Standards is recommended.

7. Argon.

8. Deionized water.

9. Yttrium standard, $5 \mu \mathrm{g} \mathrm{Y} / \mathrm{mL}$ in $5 \% \mathrm{HNO}$. Combine $50 \mathrm{~mL}$ conc. HNO3, ca. $500 \mathrm{~mL}$ deionized water, and $5 \mathrm{~mL} 1000 \mathrm{\mu g} \mathrm{Y} / \mathrm{mL}$ standard. Dilute to $1 \mathrm{I}$.

* See SPECIAL PRECAUTIONS. 
EQUIPMENT :

1. Blood collection tubes, heparinized, lead-free, specially prepared for collecting blood samples for blood lead determinations.

NOTE: Heparin may contain significant amounts of $\mathrm{Ca}, \mathrm{Cu}, \mathrm{Mn}, \mathrm{Sr}$ and $\mathrm{Zn}$ and should not be used if these elements are to be determined [3].

2. Vacutainer needles (21-gauge) and holder.

NOTE: These may be significant sources of contamination in some cases [4].

3. Tourniquet and alcohol swabs.

4. Bottles, glass or polyethylene, with PTFE-lined caps, 20-mL (e.g., scintillation vials).*

5. Inductively-coupled plasma-atomic emission spectrometer equipped for determination of elements of interest.

6. Regulator, two-stage, for argon.

7. Analytical balance, readable to $1 \mathrm{mg}$.

8. Beaker, Griffin $(50-\mathrm{mL})$ or Phillips $(125-\mathrm{mL})$, with watchglass covers.*

9. Hotplate, for use at 110 and $250^{\circ} \mathrm{C}$.

10. Pipets, 5- and 10-mL.*

11. Volumetric flasks, 5- and 10-mL and 1-L.*

12. Plastic, * glass* or single element (e.g., tantalum) knives and forceps for cutting tissue samples, as needed $[3,4,5]$.

13. Work station with plastic work surfaces, with air cleaned by a vertical, laminar flow device and high efficiency particulate air filter or by electrostatic precipitator.

14. Gloves, plastic, metal-free.

* All glassware and plasticware which contacts standards, blanks, or samples should be detergent-washed, thoroughly rinsed with tap and deionized water, soaked $12 \mathrm{hrs}$ in $10 \%(\mathrm{v} / \mathrm{v})$ HNO3 and soaked $12 \mathrm{hrs}$ in deionized water.

SPECIAL PRECAUTIONS:

Concentrated acids are extremely corrosive; work with them only in a fume hood and wear appropriate safety equipment (safety glasses or face shield, gloves and labcoet.). 
1. Collect blood samples in heparinized blood collection tubes. Mix immediately. Collect tissue samples (ca. $0.25 \mathrm{~g}$ for "dry" tissue or ca. $1 \mathrm{~g}$ for "wet" tissue) in bottles.

NOTE: If unheparinized blood collection tubes are used, freeze samples immediately.

2. Ship samples in dry ice and store frozen $\left(<15^{\circ} \mathrm{C}\right)$ prior to digestion.

\section{SAMPLE PREPARATION:}

3. Allow sample to equilibrate to room temperature.

4. Transfer an accurately weighed $10 \mathrm{~g}$ blood, $0.25 \mathrm{~g}$ "dry" tissue, or $1.0 \mathrm{~g}$ "wet" tissue to a beaker.

5. Add $10.0 \mathrm{~mL}$ digestion acid to each blood sample or $5.0 \mathrm{~mL}$ digestion acid to each tissue sample. Heat at $110^{\circ} \mathrm{C}$ for 2 hrs.

NOTE: start reagent blanks, in triplicate, at this step.

6. Increase hotplate temperature to $250^{\circ} \mathrm{C}$ and heat until ca. $1 \mathrm{mI}$ (for blood) or ca. $0.5 \mathrm{~mL}$ (for tissue) remains (2 to 3 hrs).

7. Allow beaker to cool.

8. Choose one of the following:

a. External standard method. Transfer contents of beaker to a volumetric flask (10 $\mathrm{mL}$ for blood; $5 \mathrm{~mL}$ for tissue). Dilute to the mark with deionized water.

b. Internal standard method. Add, via pipet, $10.0 \mathrm{~mL}$ (for blood) or $5.0 \mathrm{~mL}$ (for tissue) yttrium standard to the beaker.

\section{CAIIBRATION AND QUALITY CONTROL:}

9. Calibrate the spectrometer according to manufacturer's recommendations.

NOTE: Typically, an acid blank and $10 \mu \mathrm{g} / \mathrm{mL}$ multielement solutions are used.

10. Analyze a standard for every ten samples.

11. Check measurement recoveries for all elements of interest with at least three spiked, unexposed samples or with reference materials of known elemental composition. These quality control samples should constitute 15 to $20 \%$ of all samples analyzed. 
NOTE: For blood or tissue spikes, split a control sample and spike one fraction. Subtract the element quantity found in the unspiked portion from the element quantity found in the spiked portion and determine measurement recovery. Correct all samples for this measurement recovery. This is especially important for blood samples because routine interelement corrections will not adequately compensate for the high levels of iron present, which has numerous spectral emission wavelengths.

\section{MEASUREMENT :}

12. Set the spectrometer to conditions specified by the manufacturer.

13. Analyze standards and samples.

NOTE: If the values for the samples are above the range of the standards, dilute the sample solutions with $10 \% \mathrm{H}_{2} \mathrm{SO}_{4}$, reanalyze, and apply the appropriate dilution factor in calculations.

\section{CALCULATIONS :}

14. Obtain the solution concentration found for each element in the sample, $C_{s}(\mu g / m L)$, and the average blank, $\mathrm{Cb}_{b}(\mu \mathrm{g} / \mathrm{mL})$, from the measurement data.

15. According to the method of standardization, calculate the concentration, $C(\mu \mathrm{g} / \mathrm{g})$, of each element in the mass of sample taken, $M(g)$.

a. External standard method. Use the final solution volumes of sample, $V_{S}(\mathrm{~mL})$ and blank, $\mathrm{Vb}_{\mathrm{b}}(\mathrm{mL})$ :

$$
C=\frac{\left(C_{s} V_{s}-C_{b V b}\right)}{M}, \mu g / g .
$$

b. Internal standard method. Use the yttrium standard concentration, $C_{y}(\mu \mathrm{g} / \mathrm{mL})$, the volume of yttrium standard added, $V_{y}(m L)$, and the concentration of yttrium found in the sample, Csy $(\mu \mathrm{g} / \mathrm{mL})$. Treat the blank solution similarly [i.e., $\mathrm{Cb}$ is the concentration $(\mu \mathrm{g} / \mathrm{mL})$ of analyte on the blank and Cby is the concentration of yttrium in the blank]:

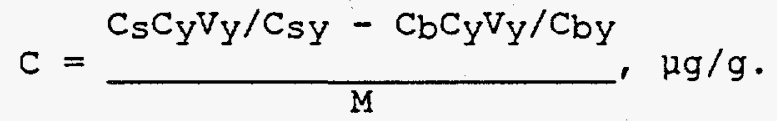

Acceptable and unacceptable levels for elements have not been determined by this method. Iyengar il reports metals concentrations in tissues and body fluids. Lauwerys i7] discusses metals and can be consulted for guidance and interpretation. For tissue, trace element 
concentrations will vary with the tissue type or organ. Iyengar [6] reports metals concentrations for different tissues of nonoccupationally exposed people. Blood metal concentrations of nonoccupationally exposed individuals are given in Table 1.

\section{REFERENCES:}

[1] Hull, R. D. ICP-AES Determination of Trace Metals in Urine, Blood and Tissue, NIOSH Internal Report (unpublished, 1984).

[2] Hull, R. D. Multielement Analysis of Industrial Hygiene Samples, NIOSH Internal Report, presented at the American Industrial Hygiene Conference, Portland, OR (May, 1981).

[3] Katz, S. A. Amer. Biotechnology Lab., 2 (4), 24-30 (1984).

[4] Versieck, J., F. Barbier, R. Cornelis and J. Hoste. Talanta, 29, 973-984 (1982).

[5] Behne, D. J. Clin. Chem. Clin. Biochem., 19, 115-120 (1981).

[6] Iyengar, G. V., W. E. Kollmer and H. J. M. Bowen. The Elemental Composition of Human Tissues and Body Fluids, Verlag Chemie., New York (1978).

[7] Lauwerys, R. R. Industrial Chemical Exposure: Guidelines for Biological Monitoring, Biomedical Publications, Davis, CA (1983).

[8] Toxic and Trace Metals in the Workplace and the Natural Environment, EnvironmentaI Sciences Associates, Inc., Bedford, MA 01730 (1981).

[9] Tipton, I. H. and J. J. Shafer. Statistical Analysis of Lung Trace Element Levels, Arch. Of Environ. Health, 8,66 (1964).

[10] Brune, D., G. Nordberg and P. O. Wester. Distribution of 23 Elements in the Kidney Liver and Lungs of Workers from a Smeltery and Refinery in North Sweden Exposed to a Number of Elements and of a Control Group, Sci. of the Total Environ., 16, 13 (1980).

[11] Mulay, I. I., R. Roy, B. E. Knox, N H. Suhr and W. E. Delaney. Trace Metal Analysis of Cancerous and Noncancerous Human Tissues, $\mathrm{J}$. of the Natl. Cancer Inst., 47, 9 (1971).

[12] Smith. R. G. A Summary of Recent Information on "Normal Levels" and "Significant Levels" of Some Inorganic Substances in Body Fluids and Tissues, presented at AIHA Annual Meeting, Detroit, MI (1961).

[13] Crable, J. V., R. G. Keenan, R. E. Kinser, A. W. Smallwood and P. A. Mauer. Metal and Mineral Concentrations in lungs of Bituminous Coal Miners, Am. Ind. Hyg. Assoc. J., 29, 106 (1968).

[14] Sweet, D. V., W. E. Crouse and J.V. Crable. Chemical and Statistical Studies of Contaminants in Urban Lungs, Am. Ind. Hyg. Assoc. J., 39, 515 (1978).

[15] Lauwerys, R. Biological Criteria for Selected Industrial Toxic Chemicals: A Review, Scand. J. Work Environ. and Health, 1, 139 (1975).

[16] Haas, W. H. , K. W. Olson, V. A. Fassel and E. L. DeKalb. Development of Multielement Sampling and Analyses Methods Using Inductively Coupled Plasma-Atomic Emission Spectroscopy, Annual Progress Report for NIOSH, Interagency Agreement NIOSH-IA-77-24 (1980).

[17] Baselt, R. C. Biological Monitoring Methods for Industrial Chemicals, Biomedical Publications, Davis, CA (1980).

[18] Goldwater, L. J. Normal Concentrations of Metals in Urine and Blood, WHO Chron., 21(5), 191 (1967). 
[19]. Bowen, H. J. M. Trace Elements in Biochemistry, Academic Press (1966).

METHOD WRITTEN BY: R. DELON HUIl, NIOSH/DPSE.

Table 1. Recovery of metals from blood $[1,2]$.

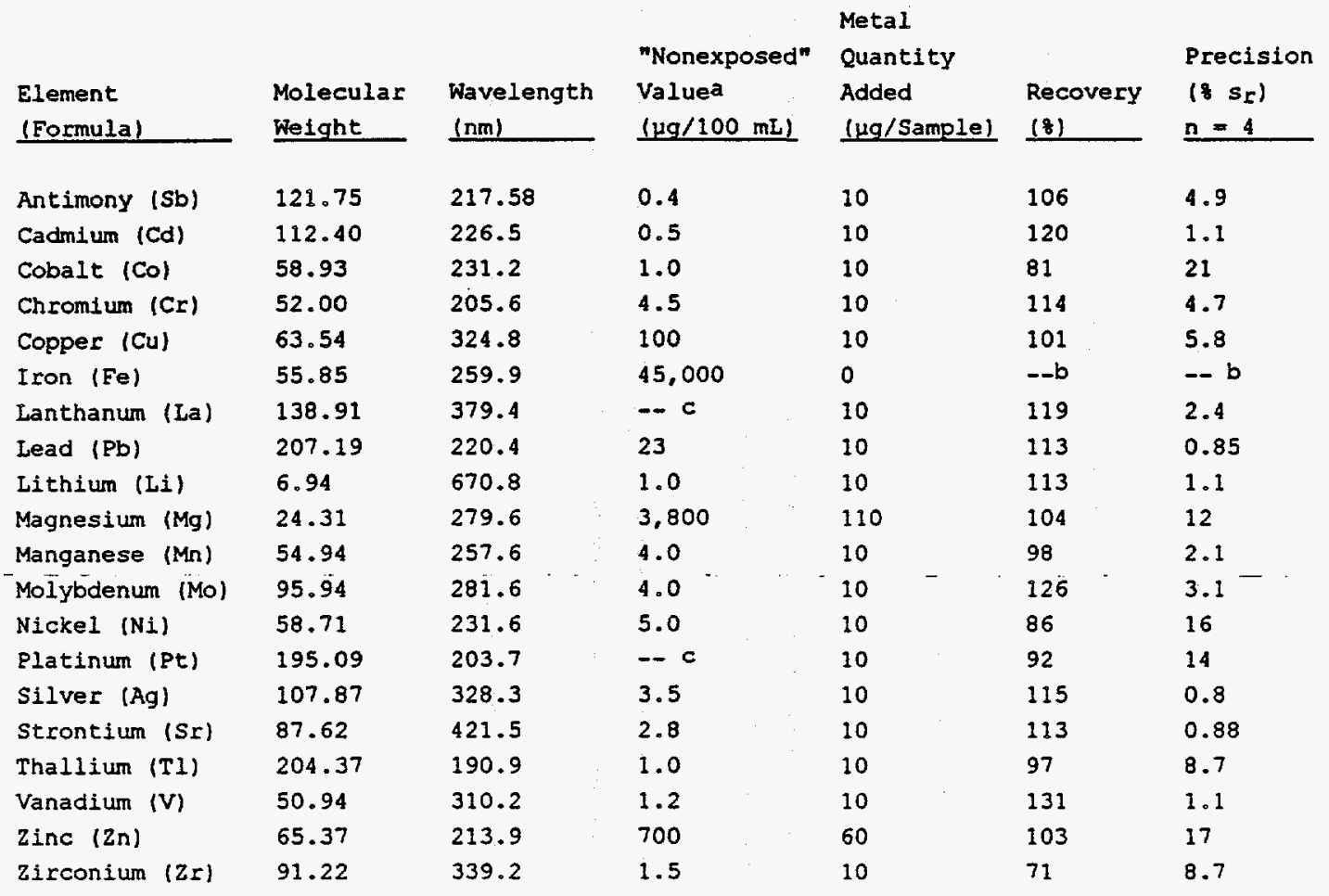

a "Nonexposed" value is the average concentration for the respective element in blood of non-occupationally exposed individuals. These values were tabulated from References [6] through [19].

b Recovery not determined (blood Fe concentration was above quantitation limit of spectrometer).

c Concentration not reported. 
Appendix $\mathrm{H}$

A method for the determination of urine selenium - Condensed version

\section{Application}

Optimal working range lies between 0.3 and 6 umole/ $L$

\section{Principle}

A urine aliquot is digested in a mixture of $\mathrm{HNO}_{3}$ and $\mathrm{H}_{2} \mathrm{O}_{2}$. The sample is then directly analyzed by graphite furnace atomic absorption using Zeeman background correction (ZL-4100). A mixture of copper and magnesium nitrate is used as modifier. Calibration is performed in a urine matrix.

3. Linearity and detection limit

Linearity: 0-6 umol/L

Detection limit: $0.3 \mathrm{umol} / \mathrm{L}$

\section{Normal}

$1 \mathrm{umol} / \mathrm{L}$

\section{Sampling preparation}

In a $115 \mathrm{~mL}$ polypropylene tube, add $1 \mathrm{~mL}$ of urine, $500 \mathrm{uL}$ of $\mathrm{HNO}_{3} \mathrm{c}$ and 500 $\mathrm{UL}$ of of $\mathrm{H}_{2} \mathrm{O}_{2} 50 \%$. Screw cap on tightly and place in a water bath at $80^{\circ}$ for 1 hour.

Directly transfer nto autosampler cups adn use $\mathrm{Cu} 11 \%-\mathrm{Mg}\left(\mathrm{NO}_{3}\right)_{2} 2 \%$ as chemical modifier.

Procedure performed by Le Centre deToxicologie du Quebec. 2705, Boul. Laurier. Sainte-Foy, Quebec, Canada G2V 4G2

Bureau (418) 654-2254

Laboratoire (418) 654-2100

Fax: (418) 654-2754

Personal Communication, Weber October 17, 1994. 
a "Nonexposed" value is the average concentration for the respective element in blood of non-occupationally exposed individuals. These values were tabulated from References [6] through [19].

b Recovery not determined (blood Fe concentration was above quantitation limit of spectrometer).

c Concentration not reported. 


\section{Appendix 1}

A method for the determination of serum selenium Condensed version

\section{Application}

Optimal working range lies between 0.5 and 5 umole/L

\section{Principle}

An aliquot of serum is diluted in $0.05 \%$ Triton $X-100$ and analyzed by graphite furnace atomic absorption using Zeeman background correctgion (PE-5100). Paladium and magnesium nitrate are used as modifiers. Calibration is performed in a normal serum.

3. Linearity and detection limit

Linearity: 0.5 umol/L Detection limit: 0.2 umol/L

\section{Normal}

\section{1-2 umol/L}

\section{Sampling preparation}

In a $1.5 \mathrm{~mL}$ autosampler cup, pupet $200 \mathrm{uL}$ of Triton $\mathrm{X}-1000.05 \%$. Add $100 \mathrm{uL}$ of serum. Mix gently. Modifier is $\mathrm{Pd} 0.25 \%$ and $\left.\mathrm{Mg}(\mathrm{NO})_{3}\right)_{2} 0.25 \%$.

\section{References}

J. Neve, S. Chamart, L. Molle. Optimization of a direct procedure for the determination of selenium in plasma and erythrocutes using Zeeman effect atomic absorption spectroscopy. Trace element - Analytical Chemistry in medecine and biology, 4 (1987).

Procedure performed by Le Centre de toxicologie du Quebec. 2705, Boul. Laurier. Sainte-Foy, Quebec, Canada G2V 4G2

Bureau (418) 654-2254

Laboratoire (418) 654-2100

Fax: (418) 654-2754

Personal Communication, Weber October 17, 1994. 


\title{
METHOD 27 - DETERMINATION OF SELENIUM IN HUMAN TISSUES, FLUIDS AND EXCRETA BY HYDRIDE GENERATION AND ATOMIC-ABSORPTION SPECTROMETRY
}

\author{
K.S. Subramanian
}

\section{SCOPE AND FIELD OF APPLICATION}

This method is suitable for the determination of selenium (Se) in human whole blood, plasma, red cells, urine, kidney cortex, kidney medulla and liver. The method can probably be extended to other types of human tissue samples and physiological fluids.

The method is applicable to samples containing 0.05 to $0.5 \mu \mathrm{g} \mathrm{Se} / \mathrm{g}$ of wet tissue.

Because of the wide range of apparatus available for applying this family of techniques, the detection limit for Se is highly variable. Using a Perkin-Elmer MHS20 hydride generation system, Llyod et al. (1982) obtained a detection limit of $13.5 \mu \mathrm{g} / \mathrm{L}$ for Se in blood and plasma; using an automatic hydride evolution procedure, Subramanian and Meranger (1982) obtained a detection limit of $10 \mu \mathrm{g} / \mathrm{kg}$ for Se in human liver and kidney samples.

\section{REFERENCES}

Analytical Methods Committee (1979) Determination of small amounts of selenium in organic matter. Analyst, 104, 778-787

Clinton, O.E. (1977) Determination of selenium in blood and plant material by hydride generation and atomic absorption spectroscopy. Analyst, 102, 187-192

Kneip, T.J., Ajemian, R.S., Driscoll, J.N., Grunder, F.I., Kornreich, L., Loveland, J.W., Moyers, J.L. \& Thompson, R.J. (1977) Arsenic, selenium and antimony in urine and air: analytical method by hydride generation and atomic absorption spectroscopy. Health Lab. Sci., 14, 53-58

Lloyd, B., Holt, P. \& Delves, H.T. (1982) Determination of selenium in biological samples by hydride generation and atomic absorption spectroscopy. Analyst, 107, 927-933

Subramanian, K.S. \& Méranger, J.C. (1982) Rapid hydride evolution-electrothermal atomisation atomic-absorption spectrophotometric method for determining arsenic and selenium in human kidney and liver. Analyst, 107, 157-162 


\section{DEFINITIONS}

The detection limit is defined as the concentration of Se equal to three times the standard deviation of the Se concentration of the blank.

\section{PRINCIPLE}

- The sample is digested with a mixture of nitric, perchloric and sulfuric acids to destroy the organic matter and $\mathrm{Se}[\mathrm{VI}]$ is reduced to Se[IV] using hydrochloric acid $(\mathrm{HCl})$. Se[IV] hydride is then formed in the acidic solution with sodium tetrahydroborate [III] and is subsequently decomposed in a heated cell, where the Se concentration is measured by atomic absorption spectrometry (AAS).

\section{HAZARDS}

Selenium is toxic. It is desirable to practice the usual methods of safe handling and disposal of all solutions containing Se. Hot acid digestion mixtures should be handled in a ventilated hood and resistant gloves and face mask should be worn. Concentrated perchloric acid will explode in contact with organic materials, or by shock or heat.

\section{REAGENTS ${ }^{1}$}

NOTE: The reagent concentrations given below refer to the hydride generation system used in the author's laboratory. The volume and concentrations of the reagents to be used may vary with the type of hydride generation system employed. Use analytical grade reagents and glass-distilled, deionized water throughout.

Argon

Nitric acid

$68-71 \%$, specific gravity 1.42 , 'Suprapure' or equivalent, or distil from glass and discard the first and final $10 \%$.

Perchloric acid

Sulfuric acid

Hydrochloric acid
$72 \%$, specific gravity 1.67 .

$90 \%$, specific gravity 1.84 .

Approximately $6 \mathrm{~mol} / \mathrm{L}$. Dilute $540 \mathrm{~mL}$ of $\mathrm{HCl}$ (36-38\%, specific gravity 1.18 ) to $1 \mathrm{~L}$ with water.

\footnotetext{
${ }^{1}$ Reference to a company and/or product is for the purpose of information and identification only and does not imply approval or recommendation of the company and/or product by the International Agency for Research on Cancer, to the exclusion of others which may also be suitable.
} 
Hydrochloric acid

Sodium tetrahydroborate [III] solution

Standard Se solution A

Standard Se solution B

Standard Se solution C

Bovine liver powder
Approximately $0.5 \mathrm{~mol} / \mathrm{L}$. Dilute $50 \mathrm{~mL}$ of $\mathrm{HCl}$ (36-38\%, specific gravity 1.18 ) to $1 \mathrm{~L}$ with water.

$10 \mathrm{~g} / \mathrm{L}$. Dissolve $10 \mathrm{~g}$ of sodium tetrahydroborate [III] (Alfa Inorganics) and $2 \mathrm{~g}$ of sodium hydroxide in $1 \mathrm{~L}$ of glass-distilled water. Keep refrigerated in a tightly capped polyethylene bottle until ready for use. The solution is stable for at least one week under these conditions.

$1 \mathrm{~g} / \mathrm{L}$. Dissolve $1.000 \mathrm{~g}$ of black Se (purity = $99.9 \%$ ) in about $10 \mathrm{~mL}$ of $\mathrm{HNO}_{3}$ by warming. Dilute to $1 \mathrm{~L}$ with water and mix well.

$10.0 \mathrm{mg} / \mathrm{L}$. Dilute $10.0 \mathrm{~mL}$ of standard Se solution A to $1 \mathrm{~L}$ with $0.1 \mathrm{~mol} / \mathrm{L} \mathrm{HCl}$.

$0.10 \mathrm{mg} / \mathrm{L}$. Dilute $10.0 \mathrm{~mL}$ of standard Se solution B to $1 \mathrm{~L}$ with $0.1 \mathrm{~mol} / \mathrm{L} \mathrm{HCl}$.

Standard Reference Material 1577 (US National Bureau of Standards).

7. APPARATUS ${ }^{1}$

Usual laboratory equipment and the following items (Fig. 1):

Atomic absorption spectrophotometer

Se hollow cathode lamp (HCL), or electrodeless discharge lamp (EDL)
Many commercially-available instruments are acceptable. (The author used a varian Techtron Model AA-5 atomic absorption spectrometer. More sophisticated versions are now available.)

Any commercially-available lamp. An EDL is recommended. The HCL may be used with reduced sensitivity. The lamp should emit monochromatic radiation at $196 \mathrm{~nm}$, corresponding to the resonance wavelength of Se.

\footnotetext{
1 Reference to a company and/or product is for the purpose of information and identification only and does not imply approval or recommendation of the company and/or product by the International Agency for Research on Cancer, to the exclusion of others which may also be suitable.
} 
Atomic reservöir (see

Fig. 1)
Preferably an electrically-heated, silica tube furnace. The temperature of the furnace may be regulated by means of an 0-110 V Variac transformer. (The tube furnace may also be heated with an air-acetylene flame.) Satisfactory results may be obtained using a silica tube of approximately $15.0 \mathrm{~cm}$ length and $1.2 \mathrm{~cm}$ i.d., with a central sidearm $(0.4 \mathrm{~cm}$ i.d.) for 'hydride' introduction.

Autosampler

Strip chart recorder

$10 \mathrm{mV}$ full-scale

Hydride generation system

Single injection system or continuous evolution system. Automatic continuous evolution systems produce better precision and lower detection limits than single injection systems. See Subramanian and Méranger (1982).

Digestion vessels _ _ - Pyrex glass tubes $(28 \times 133 \mathrm{~mm}, 50 \mathrm{~mL}$-eapacity $)$ with a means of heating at a controlled rate (e.g., hot plate). Alternatively, a temperature-programmable aluminium 'block digestor' may be found to be advantageous, particularly when large numbers of samples have to be processed.

Volumetric flasks Pyrex, 20-mL (see also 9.5.4).

NOTE: Prior to analysis, rinse all glass-ware with hot water, hot $\mathrm{HNO}_{3}: \mathrm{H}_{2} \mathrm{SO}_{4}$ $(1: 1, v / v)$, hot tap water and distilled, deionized water. Dry in oven at $110^{\circ} \mathrm{C}$ or at ambient temperature in air.

\section{SAMPLING}

Proceed from a representative sample and store in such a way that deterioration and change in composition are prevented (see Chapter 10, Sampling, storage and pretreatment of biological material).

\section{PROCEDURE}

\subsection{Blank test}

Carry out a blank test in parallel with the analysis of the sample, using procedure 9.4-9.7, but omitting the sample (9.4.1).

\subsection{Check test}

Carry out a check test by analysing the NBS standard reference material, bovine liver, using procedure 9.4-9.7. 
Fig. 1. Schematic representation of autosampler, proportionating pump and atomic absorption spectrometer

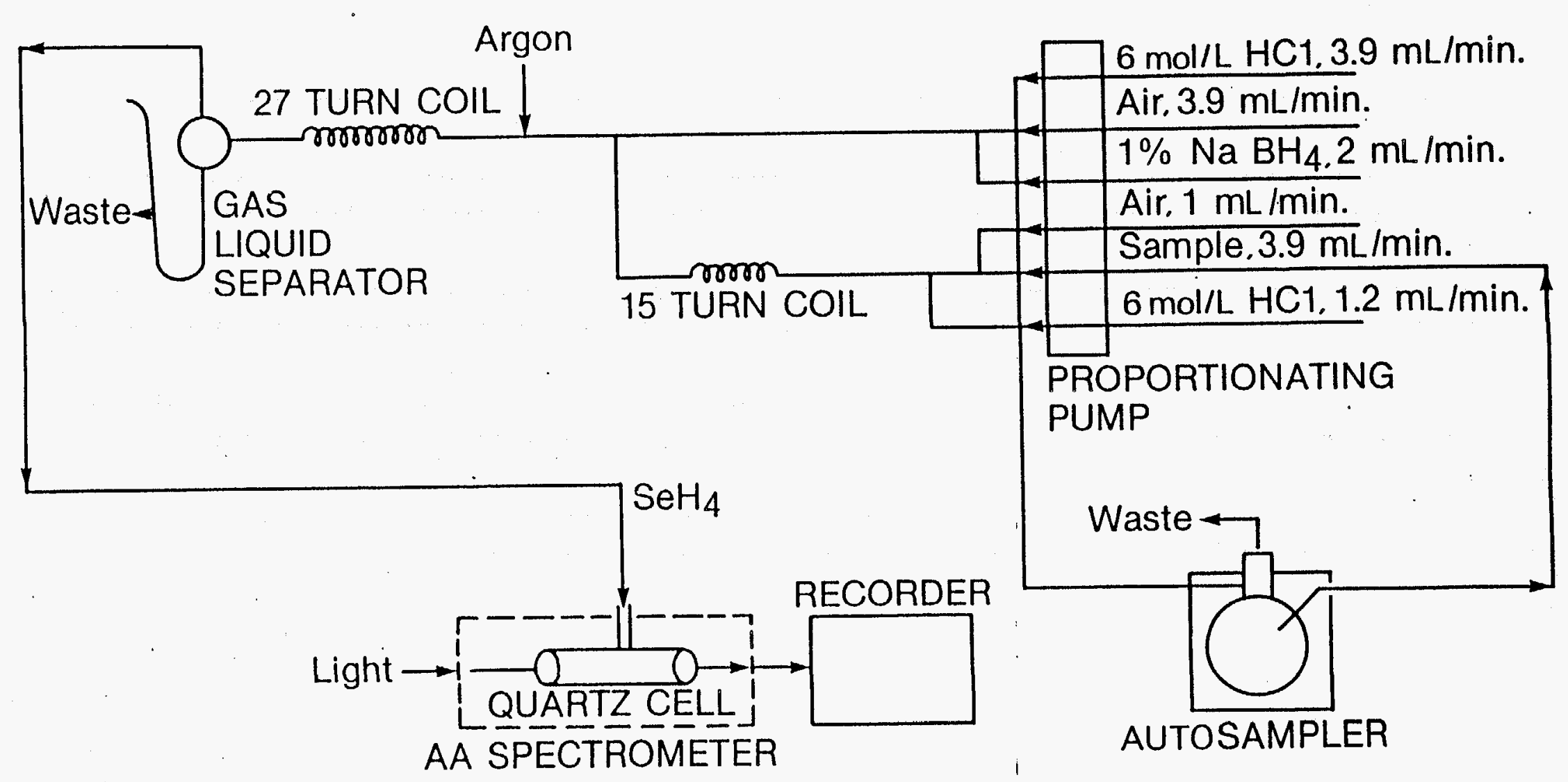




\subsection{Test portion}

Weigh accurately 1.00 to $2.00 \mathrm{~g}$ of representative tissue sample or measure accurately 0.10 to $5.0 \mathrm{~mL}$ of blood or plasma.

\subsection{Digestion of sample}

The digestion procedure given below is that recommended by the Analytical .Methods Committee (1979), with slight modifications.

9.4.1 Place duplicate test portions in two Pyrex Tubes $(28 \times 133 \mathrm{~mm})$.

9.4.2 Add $10 \mathrm{~mL}$ of nitric acid and $2 \mathrm{~mL}$ of perchloric acid.

9.4.3 Heat cautiously on an electric hot plate (sand-bath) or a block digestor until the initial foaming and bumping subsides, the sample is solubilized and the volume is reduced to about $5 \mathrm{~mL}$. Cool to room temperature.

9.4.4 Add $5 \mathrm{~mL}$ of nitric acid and $5 \mathrm{~mL}$ of sulfuric acid.

9.4.5 Return the tube to the heater and continue to heat until the solution becomes clear and colourless (or pale yellow), and dense white fumes of sulfur trioxide begin to appear. (Caution: If the digest begins to darken during heating after the addition of nitric acid-sulfuric acid solution, prevent the darkening by the cautious addition of $1 \mathrm{~mL}$ increments of nitric acid.)

9.4.6 Allow the solution to cool to room temperature.

9.5 Reduction of Se[VI] to Se[IV]

9.5.1 Dilute the solution (9.4.6) to $5 \mathrm{~mL}$ with $0.5 \mathrm{~mol} / \mathrm{L}$ hydrochloric acid.

9.5.2 Add sufficient concentrated $\mathrm{HCl}$ to produce a solution approximately 6 $\mathrm{mol} / \mathrm{L}$ in $\mathrm{HCl}$.

9.5.3 Boil the solution gently for $5 \mathrm{~min}$, then allow to cool to room temperature.

9.5.4 Transfer to a volumetric flask of a suitable volume (which will depend on the Se content of the sample and the sensitivity of the instrument) and dilute to the mark with water. Retain for AAS (9.7).

\subsection{AAS operating conditions}

9.6.1 Allow the atomic absorption spectrometer to warm up and the silica tube furnace to attain thermal equilibrium. The following operating conditions are optimum for the Varian Techtron Model AA-5 spectrometer: 


$\begin{array}{ll}\text { Wavelength } & 196.0 \mathrm{~nm} \\ \text { Band width } & 0.3 \mathrm{~nm} \\ \text { Hollow-cathode (Cathodeon) lamp current } & 4,5 \mathrm{~mA} \\ \text { Damping } & \text { maximum (D) } \\ \text { Argon flow rate } & 400 \mathrm{~mL} / \mathrm{min} \\ \text { Sample time } & 1 \mathrm{~min} \\ \text { Wash time } & 2 \mathrm{~min} \\ \text { Recorder span } & 5.0 \mathrm{mV} \text { full-scale } \\ \text { Chart speed } & 0.6 \mathrm{~cm} / \mathrm{min} .\end{array}$

NOTE: The optimum conditions will depend on the particular atomic absorption spectrometer employed. The analyst should determine the optimum operating conditions experimentally for his instrument.

9.6.2 Turn on the argon flow at the pre-determined flow rate.

9.6.3 Insert the Technicon manifold tubes into $6 \mathrm{~mol} / \mathrm{L} \mathrm{HCl}$ and $1 \%$ sodium tetrahydroborate [III], as shown in Fig. 1. (Caution: These reagent concentrations may vary with the hydride generation system employed. The analyst is therefore advised to determine his own optimum solution conditions experimentally.)

9.6.4 Start the Technicon proportionating pump.

9.6.5 When the system has attained equilibrium as indicated by the minimal baseline noise on the strip-chart recorder, adjust the atomic absorption spectrometer to zero absorbance.

\subsection{Selenium determination}

9.7.1 Transfer $3-4 \mathrm{~mL}$ of the solution from 9.5.4 into a 5 -mL disposable polypropylene cup in the autosampler.

9.7.2 Switch on the autosampler and record the Se atomic absorption peak.

9.7.3 Repeat 9.7.1 and 9.7.2 three times and record average absorption peak value for the four measurements.

\subsection{Preparation of calibration graph}

9.8.1 Transfer into a series of Pyrex test tubes $(28 \times 133 \mathrm{~mm})$ 0.0, 1.0, 2.0, 4.0, $6.0,8.0$ and $10.0 \mathrm{~mL}$ of standard Se solution $\mathrm{C}$, each in duplicate.

9.8.2 Add enough water to bring the total volume in each tube to approximately $10 \mathrm{~mL}$.

9.8.3 Proceed as instructed in steps 9.4.2 to 9.5.3, inclusive. 
9.8.4 Transfer the solutions from 9.8 .3 into $20-\mathrm{mL}$ volumetric flasks and make up to the mark with water.

9.8.5 Transfer 3-4 $\mathrm{mL}$ of each solution into 5-mL cup in the autosampler and proceed as in 9.7.2 and 9.7.3.

9.8.6 Plot a calibration graph of absorbance-peak height versus concentration of $\mathrm{Se}(0.0,5.0,10.0,20.0,30.0,40.0$ and $50.0 \mathrm{ng} \mathrm{Se} / \mathrm{mL})$. Prepare a new calibration curve daily. ${ }^{\circ}$

\section{METHOD OF CALCULATION}

\subsection{Selenium in human whole blood and serum}

Using the absorption-peak height (9.7.3) and the calibration curve (9.8.6), obtain the mass concentration, $\rho(\mu \mathrm{g} / \mathrm{L})$, of Se in whole blood or serum by multiplying the mass concentration of the final solution (9.5.4) by the dilution factor, $\mathrm{V} / \mathrm{v}$, where

$\mathrm{V}=$ volume of solution in $9.5 .4(\mathrm{~mL})$

$\mathrm{v}=$ volume of blood or serum in 9.4.1 (mL).

\subsection{Selenium in urine}

The Se content of urine is determined as in 10.1, but may be expressed in three different ways: (i) $\mu \mathrm{g}$ of $\mathrm{Se} / \mathrm{L}$ of urine; (ii) $\mu \mathrm{g}$ of Se/24-h urine (i.e., total volume of urine collected over a 24 -h period); (iii) $\mu \mathrm{g}$ of $\mathrm{Se} / \mathrm{g}$ of creatinine in urine.

When expressing the Se content either as (i) or (ii) above, the use of a correction factor to normalize to an average specific gravity of 1.024 is recommended.

Thus, the corrected $\mu \mathrm{g} \mathrm{Se} / \mathrm{L}$ or $24-\mathrm{h}$ urine is given by

$$
\mu \mathrm{g} / \mathrm{L}(\text { or } \mu \mathrm{g} / 24 \mathrm{~h}) \times \frac{1.024-1.000}{\text { sp. gr. }-1.000}
$$

where

sp. gr. = measured specific gravity at room temperature (The specific gravity may be measured with the use of a calibrated specific gravity meter or urinometer).

\subsection{Selenium in tissues}

The mass fraction, $\omega(\mathrm{mg} / \mathrm{kg})$ of Se in tissues may be expressed as $\mathrm{mg} \mathrm{Se} / \mathrm{kg}$ of wet tissue, as $\mathrm{mg} \mathrm{Se} / \mathrm{kg}$ of dry tissue, or as $\mathrm{mg} \mathrm{Se} / \mathrm{kg}$ of ash (in which case the 
tissue sample will have to be ashed prior to acid digestion; it is important to ensure that no loss of Se occurs by volatilization during ashing).

The mass fraction is given by

$\omega=\rho V / m$

where

$\rho=$ mass concentration of Se in final solution, $9.5 .4(\mathrm{mg} / \mathrm{L})$

$\mathrm{m}=$ mass of test portion (wet, dry or ashed) in 9.4.1 (g) and

$\mathrm{V}$ is defined in 10.1 .

\section{REPEATABILITY AND REPRODUCIBILITY}

\subsection{Repeatability}

For human liver and kidney samples analysed on the same day, Subramanian and Méranger (1982) obtained coefficients of variation $(n=20)$ of 21,12 and $7 \%$ at $0.05,0.10$ and $0.20 \mu \mathrm{g}$ Se per $\mathrm{g}$ of wet tissue, using the above procedure.

Lloyd et al. (1982) obtained coefficients of variation $(\mathrm{n}=20)$ of 4.5 and $4.0 \%$ at $143.8 \mu \mathrm{g} \mathrm{Se} / \mathrm{L}$ of whole blood and $120.4 \mu \mathrm{g} \mathrm{Se} / \mathrm{L}$ of plasma, respectively, using the Perkin-Elmer Model MHS20 Hydride Generation System.

\subsection{Reproducibility}

No data available.

\section{NOTES ON PROCEDURE}

Not applicable.

\section{SCHEMATIC REPRESENTATION OF PROCEDURE}

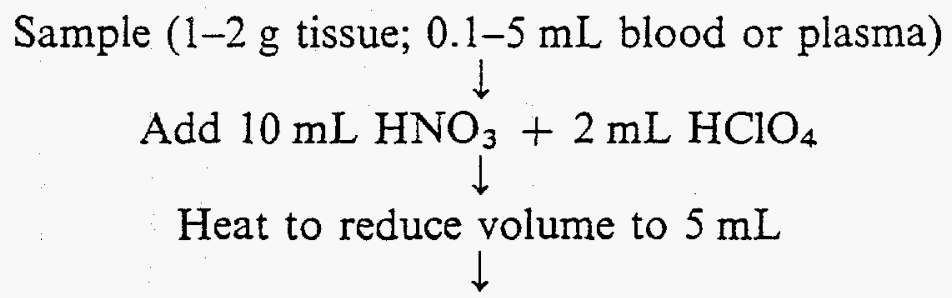


Cool to room temperature<smiles>CCCCCCCCCCC(C)(C)C</smiles>

Heat until the solution is clear and colourless

or pale yellow

Cool to room temperature

Dilute to $5 \mathrm{~mL}$ with $0.5 \mathrm{~mol} / \mathrm{L} \mathrm{HCl}$<smiles>[AlH2]</smiles>

Add conc. $\mathrm{HCl}$ to obtain concentration of $\sim 6 \mathrm{~mol} / \mathrm{L}$

Transfer 3-4 $\mathrm{mL}$ into autosampler cup<smiles>[CH][AlH2]</smiles><smiles>[AlH2]</smiles>

Generate the hydride automatically

- under optimized conditions -

$\downarrow$

Decompose the hydride, atomize the Se and measure its atomic absorption signal under optimized conditions<smiles>C[AlH]</smiles>

Determine Se content of sample by reference to calibration graph

14. ORIGIN OF THE METHOD

Health and Welfare Canada

Health Protection Branch .

Environmental Health Centre

Tunney's Pasture

Ottawa, Ontario K1A OL2

Canada

Contact point: Dr K.S. Subramanian 


\title{
Appendix K \\ METHOD 28 - DETERMINATION OF SELENIUM IN PLASMA AND SERUM BY ELECTROTHERMAL ATOMIZATION-ATOMIC ABSORPTION SPECTROMETRY
}

\author{
K.S. Subramanian
}

?

\section{SCOPE AND FIELD OF APPLICATION}

This method is suitable for the determination of selenium (Se) in microlitre volumes of human serum and plasma. The detection limit is $2.6 \mu \mathrm{g} / \mathrm{L}$ and the total time required for analysis is about $8 \mathrm{~min}$.

\section{REFERENCE}

Alfthan, G. \& Kumpulainen, J. (1982) Determination of selenium in small volumes of blood plasma and serum by electrothermal atomic absorption spectrometry. Anal. Chim. Acta, 140, 221-227

\section{DEFINITIONS}

The detection limit is defined as three times the standard deviation of the Se concentration in the blank.

\section{PRINCIPLE}

The serum or plasma sample is diluted ten-fold with a solution containing nickel and nitric acid. The Se content of this matrix-modified solution is then determined by the method of standard addition, using graphite furnace atomic absorption spectrophotometry.

\section{HAZARDS}

Selenium is toxic. It is desirable to practice the usual methods of safe handling and disposal of all solutions containing Se. 


\section{REAGENTS 1} noted.

Use the purest available reagents and ultrapure water throughout, except as

Ni[II] solution

Nitric acid

Standard Se solution A

Standard Se solution B
$2.5 \%(25 \mathrm{~g} / \mathrm{L})$. Dissolve $12.3 \mathrm{~g}$ of $\mathrm{Ni}\left(\mathrm{NO}_{3}\right)_{2} \cdot 6 \mathrm{H}_{2} \mathrm{O}$ in $100 \mathrm{~mL}$ of water. Store in a clean $125-\mathrm{mL} \mathrm{Nal}$ gene polyethylene bottle equipped with screw-cap.

Approximately $0.72 \mathrm{~mol} / \mathrm{L}$. Dilute $46.0 \mathrm{~mL}$ of nitric acid (68-71\%, specific gravity, 1.42, ultrapure grade) to $1 \mathrm{~L}$ with water and store in a clean Nalgene polyethylene bottle with screw-cap.

$1 \mathrm{~g} \mathrm{Se} / \mathrm{L}$. Dissolve $1.450 \mathrm{~g}$ of Se dioxide (purity $=$ $99.9 \%$ ) in $1 \mathrm{~mL}$ of concentrated $\mathrm{HCl}(36-38 \%$, specific gravity, 1.18). Dilute to $1 \mathrm{~L}$ with water.

$1 \mathrm{mg} \mathrm{Se} / \mathrm{L}$. Dilute $1.0 \mathrm{~mL}$ of standard Se solution A to $1 \mathrm{~L}$ with ultrapure water.

\section{APPARATUS ${ }^{1}$}

Atomic absorption spectrophotometer

Graphite furnace

Background corrector

Se hollow cathode lamp (HCL) or electrodeless discharge lamp (EDL)

Other accessories

Micropipettes and pipette tips
Many commercially-available instruments are suitable (e.g., Perkin-Elmer Model 4000 atomic absorption spectrophotometer).

Any commercially-available furnace (e.g., a PerkinElmer Model HGA-500 graphite furnace).

Deuterium or hydrogen continuum lamp.

Any commercially-available lamp. An EDL is recommended. The HCL may be used with reduced sensitivity.

Autosampler; printer; recorder. (These are desirable, but not essential).

Any available brand (e.g., Eppendorf).

\footnotetext{
${ }^{1}$ Reference to a company and/or product is for the purpose of information and identification only and does not imply approval or recommendation of the company and/or product by the International Agency for Research on Cancer, to the exclusion of others which may also be suitable.
} 
Volumetric flasks

$1.0-\mathrm{mL}$, borosilicate glass

Vortex mixer

Nalgene polyethylene $\quad 125-$ and $1000-\mathrm{mL}$

bottles

NOTE: Prior to analysis, ${ }^{2}$ wash all lab-ware with detergent, soak in $10 \%$ analytical reagent grade nitric acid for at least $4 \mathrm{~h}$ and rinse at least six times with ultrapure water.

\section{PROCEDURE}

\subsection{Blank test}

Carry out a blank test in parallel with the analysis of the sample, using procedure 9.4.1 to 9.5.6, but omitting the test portion in 9.4.1.

\subsection{Check test}

Not applicable.

\subsection{Test portion}

$100 \mu \mathrm{L}$ of serum or plasma.

\subsection{Sample preparation}

9.4.1 Pipette $100 \mu \mathrm{L}$ of serum or plasma into each of five $1.0 \mathrm{~mL}$ volumetric flasks.

9.4.2 Add $100 \mu \mathrm{L}$ of $2.5 \% \mathrm{Ni}[\mathrm{II}]$ to each flask.

9.4.3 Add $100 \mu \mathrm{L}$ of $0.72 \mathrm{~mol} / \mathrm{L}$ nitric acid to each flask.

9.4.4 Add, respectively, $0,10,20,30$ and $40 \mu \mathrm{L}$ of standard Se solution B to the five volumetric flasks.

9.4.5 Vortex each solution vigorously for $30 \mathrm{~s}$, then make up to $1.0 \mathrm{~mL}$ with ultrapure water and $\mathrm{mi}$ - thoroughly.

\subsection{Selenium determination}

9.5.1 Inject $20 \mu \mathrm{L}$ of solution 9.4.5 from the first flask (containing no added Se) into the pyrocoated graphite tube. 
Table 1. Instrumental conditions for the determination of selenium in serum and plasma (wavelength $296.0 \mathrm{~nm}$, spectral bandwidth $0.7 \mathrm{~nm}$, scale expansion 10X, background correction, peak height mode, $20 \mathrm{~mL}$ sample)

\begin{tabular}{|c|c|c|c|c|c|}
\hline Step & $\begin{array}{l}1 \\
\text { Dry }\end{array}$ & $\begin{array}{l}2 \\
\text { Dry }\end{array}$ & $\begin{array}{l}3 \\
\text { Asn }\end{array}$ & $\begin{array}{l}4 \\
\text { Atomize }\end{array}$ & $\begin{array}{l}5 \\
\text { Clean }\end{array}$ \\
\hline Temperature $\left({ }^{\circ} \mathrm{C}\right)$ & 70 & 110 & 1100 & 2400 & 2700 \\
\hline Ramp time(s) & 10 & 30 & 30 & 0 & 1 \\
\hline Hold time(s) & 0 & 20 & 20 & 4 & 2 \\
\hline Internal gas (mL Ar/min) & 300 & 300 & 300 & 20 & 300 \\
\hline
\end{tabular}

- From Alfthan \& Kumpulainen, 1982.

9.5.2 Atomize the Se under the optimized instrumental conditions given in Table 1 (see 12, Notes on Procedure).

9.5.3 Record the absorbance-peak height.

9.5.4 Repeat steps 9.5.1 to 9.5.3 at least two more times and calculate the mean absorbance-peak height from the three injections.

9.5.5 Proceed as in steps 9.5.1 to 9.5.4 for the second, third, fourth and fifth flask (i.e., for 10, 20, 30 and $40 \mathrm{ng}$ of added $\mathrm{Se} / \mathrm{mL}$ ).

9.5.6 Prepare a linear regression standard addition plot from the above data (abcissa: Se spike concentration, $\mu \mathrm{g} / \mathrm{L}$; ordinate: absorbance-peak height).

NOTE: For a serum sample diluted ten-fold, the method gives a standard addition graph which is linear up to $100 \mu \mathrm{g} \mathrm{Se} / \mathrm{L}$.

\section{METHOD OF CALCULATION}

Determine the mass concentration $(\mu \mathrm{g} / \mathrm{L})$ of Se by extrapolation of the standard addition graph (9.5.6) and multiplication by a factor of ten to correct for the ten-fold dilution (9.4.5).

\section{REPEATABILITY AND REPRODUCIBILITY}

\subsection{Repeatability}

A pooled reference serum with a mean Se concentration of $87 \mu \mathrm{g} / \mathrm{L}$ gave a coefficient of variation of $4.4 \%$ (124 determinations).

\subsection{Reproducibility}

No data available. 


\title{
12. NOTES ON PROCEDURE
}

The optimum operating conditions for every atomic absorption spectrometergraphite furnace combination may not be the same as those given in Table 1. These parameters must be optimized before attempting to obtain useful measurements.

\section{SCHEMATIC REPRESENTATION OF PROCEDURE}

\author{
$100 \mu \mathrm{L}$ serum or plasma \\ Add $100 \mu \mathrm{L} 2.5 \% \mathrm{Ni}(\mathrm{II}]$ and $100 \mu \mathrm{L} \quad 0.72 \mathrm{~mol} / \mathrm{L} \mathrm{HNO}_{3}$ \\ Mix (Vortex) for $30 \mathrm{~s}$ \\ Dilute to $1 \mathrm{~mL}$ with ultrapure water \\ Inject $20 \mu \mathrm{L}$ into pyrocoated graphite tube \\ Measure atomic absorption under optimum \\ instrumental conditions \\ $\downarrow$ \\ Determine Se content of sample from \\ standard addition graph.
}

14. ORIGIN OF THE METHOD

National Public Health Institute

Helsinki 28

Finland

Contact point: K.S. Subramanian

Environmental Health Centre

Tunney's Pasture

Ottawa, Ontario K1A OL2

Canada. 


\title{
METHOD 29 - DETERMINATION OF SELENIUM IN WHOLE BLOOD AND OTHER BIOLOGICAL MATERIALS BY SPECTROFLUORIMETRY
}

\author{
H.A.M.G. Vaessen, A. van Ooik \& P.L. Schuller
}

\section{SCOPE AND FIELD OF APPLICATION}

This reference method is suitable for the determination of the selenium (Se) content of human blood, with a lower limit of $10 \mu \mathrm{g} / \mathrm{kg}$. It has also been shown to be applicable to foodstuffs and a wide range of other biological materials. A set of 5 samples and 3 calibration standards can be analysed in approximately 5 hours.

\section{REFERENCES}

Hoffman, I., Westerby, R.J. \& Hidiroglou, M. (1968) Precise fluorometric microdetermination of selenium in agricultural materials. J. Assoc. off. anal. Chem., $51,1039-1042$

Ihnat, M. (1974) Fluorometric determination of selenium in foods. J. Assoc. off. anal. Chem., 57, 368-372

Michie, N.D., Dixon, E.J. \& Bunton, N.G. (1978) Critical review of AOAC fluorometric method for determining selenium in food. J. Assoc. off. anal. Chem., 61, $48-51$

\section{DEFINITIONS}

Not applicable.

\section{PRINCIPLE}

Organic matter in the sample is digested under pressure at $150{ }^{\circ} \mathrm{C}$ in a wet decomposition vessel. The resulting solution is treated with a perchloric acid/sulfuric acid mixture. Perchloric acid is completely expelled and Se is reduced to the tetravalent state by hydrogen peroxide, then complexed at $\mathrm{pH} 1$ with 2,3-diaminonaphthalene, to form 4,5-benzopiazselenol. The piazselenol is extracted with cyclohexane and measured fluorimetrically. 


\section{HAZARDS}

The digestion procedure employs concentrated nitric, sulfuric and perchloric acids and hydrogen peroxide. These should be handled only in a ventilated fume hood and protective gloves and spectacles should be worn.

\section{REAGENTS ${ }^{1}$}

$\checkmark$

Unless otherwise stated, all reagents should be of analytical reagent quality. Water must be double-distilled (or equivalent) from an all-glass apparatus of Pyrex or other resistant glass.

Nitric acid

Perchloric acid

Sulfuric acid

Hydrogen peroxide

Buffer solution

Ammonia solution

Cyclohexane

Disodium ethylenediaminetetraacetate dihydrate

2,3-Diaminonaphthalene

Hydrochloric acid

Sulfuric acid

Dilute ammonia solution
$65 \%$ (w/w), density $1.40 \mathrm{~g} / \mathrm{mL}$. Merck 'Suprapur', or equivalent.

$70 \%(\mathrm{w} / \mathrm{w})$, density $\sim 1.67 \mathrm{~g} / \mathrm{mL}$.

$98 \%(\mathrm{w} / \mathrm{w})$, density $1.84 \mathrm{~g} / \mathrm{mL}$. Merck 'Suprapur', or equivalent.

$30 \%(w / w)$.

pH 1.00. Merck glycine-hydrochloric acid buffer.

$25 \%$ (w/w), density $0.91 \mathrm{~g} / \mathrm{mL}$. Merck 'Suprapur', or equivalent.

Spectrofluorimetric quality. Merck 'Uvasol', or equivalent.

(EDTA)

(DAN) Fluka A.G.

$0.1 \mathrm{~mol} / \mathrm{L}$.

$2.5 \mathrm{~mol} / \mathrm{L}$.

Mix 1 -yolume of $25 \%$ ammonia solution and 2 volumes of water. Prepare fresh daily.

\footnotetext{
1 Reference to a company and/or product is for the purpose of information and identification only and does not imply approval or recommendation of the company and/or product by the International Agency for Research on Cancer, to the exclusion of others which may also be suitabie.
} 
EDTA solution

DAN solution

Se dioxide

Se stock solution

Dilute stock solution

Se working solution
$0.01 \mathrm{~mol} / \mathrm{L}$. Dissolve $2.1 \mathrm{~g}$ of EDTA in $250 \mathrm{~mL}$ of water and mix.

Accurately weigh $50 \mathrm{mg}$ of DAN in a $150-\mathrm{mL}$ beaker, add $50 \mathrm{~mL}$ of $0.1 \mathrm{~mol} / \mathrm{L}$ hydrochloric acid and dissolve by warming to $50^{\circ} \mathrm{C}$ for $30 \mathrm{~min}$ on a water-bath. Purify the solution by extraction with four 5-mL portions of cyclohexane. Discard the organic layers and filter the aqueous phase through a Whatman No. 1 (or equivalent) filter paper. Prepare this reagent immediately before use.
$100 \mathrm{mg} / \mathrm{L}$. Dissolve $70.3 \mathrm{mg}$ of Se dioxide in water in a $500-\mathrm{mL}$ volumetric flask and make up to the mark with water.

$5 \mu \mathrm{g} / \mathrm{mL}$. Pipette $5.0 \mathrm{~mL}$ of $100 \mathrm{mg} / \mathrm{L}$ stock solution into a 100 -mL volumetric flask, add $2.0 \mathrm{~mL}$ of 2.5 $\mathrm{mol} / \mathrm{L}$ sulfuric acid and make up to the mark with water.

$200 \mu \mathrm{g} / \mathrm{L}$. Pipette $4.0 \mathrm{~mL}$ of dilute stock solution into a $100-\mathrm{mL}$ volumetric flask, add $2.0 \mathrm{~mL}$ of 2.5 $\mathrm{mol} / \mathrm{L}$ sulfuric acid and make up to the mark with water.

\section{APPARATUS ${ }^{1}$}

NOTE: Soak glass-ware, including reagent bottles, for $24 \mathrm{~h}$ in $4 \mathrm{~mol} / \mathrm{L}$ nitric acid and rinse twice with distilled water, then twice with double-distilled water before use. Boil the Tefion decomposition vessels for $1 \mathrm{~h}$ in a $1 \mathrm{~mol} / \mathrm{L}$ hydrochloric acid-detergent solution, rinse with water and boil another hour in $25 \%$ hydrochloric acid, then thoroughly rinse with distilled and double-distilled water and dry in a suitable oven at $120^{\circ} \mathrm{C}$.

Decomposition vessels

Round-bottom flask
See Fig. 1 (Uniseal Corporation, Haïfa, or equivalent vessels, are equally suitable). The inner Teflon vessel holds 20 to $23 \mathrm{~mL}$.

250-mL, long neck.

\footnotetext{
I Reference to a company and/or product is for the purpose of information and identification only and does not imply approval or recommendation of the company and/or product by the International Agency for Research on Cancer, to the exclusion of others which may also be suitable.
} 
VAESSEN ET AL.

Glass beads

Measuring pipettes

One-mark pipettes

Nitric acid treated and washed with water, as indicated above.

Measuring cylinders

1-, 2- and 5-mL, with glass piston (Fortuna type or equivalent).

Volumetric flasks

5-mL.

Separating funnels

, 5- and 50-mL.

100- and $500-\mathrm{mL}$.

250-mL, with Teflon stopcocks.

Argand-burners

Analytical balance

Accurate to within $0.1 \mathrm{mg}$.

$\mathrm{pH}$ meter

Accurate to within $0.05 \mathrm{pH}$-units and fitted with a combined $\mathrm{pH}$ glass electrode, reserved for the determination of $\mathrm{Se}^{-}$

Oven

Ventilated, thermostatically-controlled at $150^{\circ} \mathrm{C}$ (place in a fume hood).

Water-bath

Thermostatically-controlled at $50^{\circ} \mathrm{C}$.

Spectrofluorimeter

Ratio-recording, scanning instrument is preferred (Aminco-Bowman type SPF-500, or equivalent).

Quartz cells

Suitable for fluorimetric measurements, optical pathlength $1 \mathrm{~cm}$.

Finn-pipettes

Adjustable, to deliver volumes of 50 to $250 \mu \mathrm{L}$ and 200 to $1000 \mu \mathrm{L}$, with disposable plastic tips.

\section{SAMPLING}

Consult Chapter 10.

Homogenize a representative blood sample. If the sample comes into contact with metal parts of the homogenizer, check for Se contamination. Avoid contact with metals by using porcelain whenever possible.

\section{PROCEDURE}

\subsection{Blank test}

The reagent blank is determined with the calibration curve (9.6), which then provides an automatic blank correction. 
Fig. 1. Wet decomposition vessel (all dimensions are in $\mathrm{mm}$ )
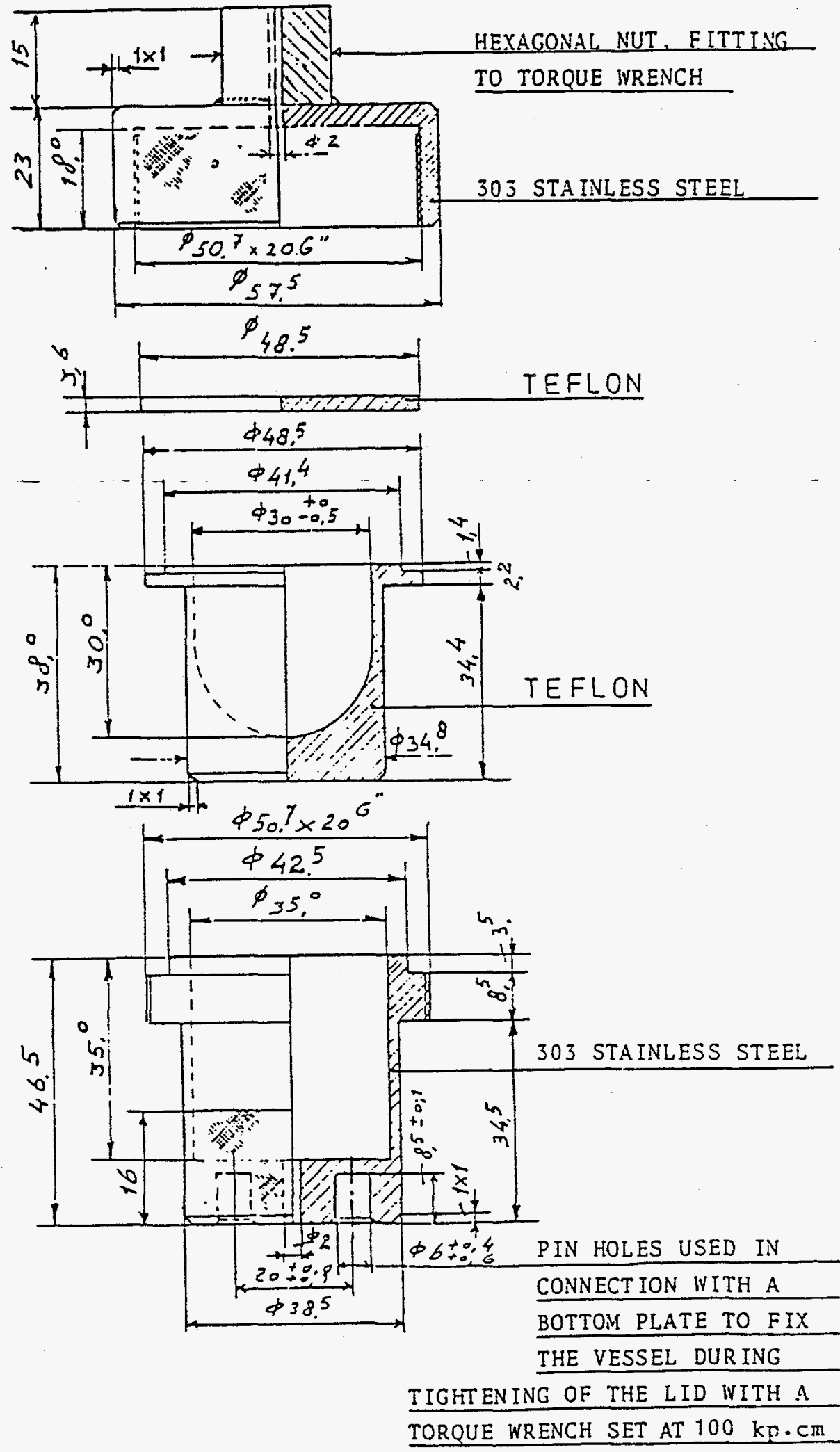


\subsection{Check test}

Not applicable.

\subsection{Test portion}

Weigh, to the nearest $0.1 \mathrm{mg}$, a homogenized test portion containing not more than $500 \mathrm{ng}$ of Se.

- For safety reasons, the test portion in the Tefion decomposition vessel should be restricted to $500 \mathrm{mg}$ ( $200 \mathrm{mg}$ dry material).

\subsection{Digestion}

9.4.1 Weigh the test portions (9.3) into decomposition vessels (Fig. 1), add 3.0 $\mathrm{mL}$ of $65 \%$ nitric acid with a measuring pipette, close the vessels and place them in an oven at $150^{\circ} \mathrm{C}$ for $10 \mathrm{~h}$. (Close the vessels with a torque wrench set at $100 \mathrm{kp} . \mathrm{cm}=4.448 \times 10^{3}$ N.m.)

9.4.2 Allow the digestion vessels to cool to room temperature and transfer the digest to a $250-\mathrm{mL}$ round-bottom flask.

9.4.3 Add three glass beads, $2 \mathrm{~mL}$ of $70 \%$ perchloric acid and $5 \mathrm{~mL}$ of $98 \%$ sulfuric acid. Mix.

9.4.4 Heat the mixture using an Argand-burner. The solution will first turn straw-yellow. Continue heating until, after vigorous swirling, the digest remains colourless and dense sulfuric acid fumes appear.

9.4.5 Cool to room temperature, rinse the neck of the flask with $5 \mathrm{~mL}$ of water, mix and reheat to fuming.

9.4.6 Allow the digest to cool to room temperature and add $1 \mathrm{~mL}$ of $30 \%$ hydrogen peroxide. Heat until small gas bubbles are no longer evolved (hydrogen peroxide is completely decomposed) and dense sulfuric acid fumes appear.

\subsubsection{Repeat 9.4.6 twice.}

9.4.8 Cool the digest to room temperature, rinse the neck of the flask with 10 $\mathrm{mL}$ of water and heat to fuming. Continue heating with evolution of fumes for a further $5 \mathrm{~min}$.

9.4.9 Cool digest to room temperature and dilute with $50 \mathrm{~mL}$ of water.

\subsection{Formation and extraction of benzopiazselenol}

9.5.1 Add $10 \mathrm{~mL}$ of EDTA solution and $7.5 \mathrm{~mL}$ of $25 \%$ ammonia to the diluted digest (9.4.9). Cool to room temperature and adjust the $\mathrm{pH}$ of the solution to 1.0 with dilute ammonia (Use a pH meter). 
9.5.2 Add $5.0 \mathrm{~mL}$ of DAN solution with a pipette and place in a water-bath at $50^{\circ} \mathrm{C}$ for $30 \mathrm{~min}$. Carry out following steps in subdued light.

9.5.3 Cool solution to room temperature and quantitatively transfer to a 250-mL separating funnel, using as little water as possible for rinsing. Add $5.0 \mathrm{~mL}$ of cyclohexane.

9.5.4 Allow the layers to separate and discard the aqueous layer. Wash the organic layer with $25 \mathrm{~mL}$ of $0.1 \mathrm{~mol} / \mathrm{L}$ hydrochloric acid (shake vigorously for $30 \mathrm{~s}$ ), allow the layers to separate and discard the lower layer. Retain cyclohexane extract for Se determination.

\subsection{Calibration graph}

Establish a calibration graph for each series of samples.

9.6.1 Using Finn-pipettes, add to three decomposition vessels amounts of Se working standard solutions containing 0 (blank), $1 / 2 \mathrm{x}$ and $\mathrm{x} n \mathrm{ng}$ Se, where $x$ is the maximum quantity of Se considered to be present in the test portions.

9.6.2 To each vessel, add $3.0 \mathrm{~mL}$ of $65 \%$ nitric acid. Close the vessels and place them in an oven at $150^{\circ} \mathrm{C}$ for $10 \mathrm{~h}$. Cool to room temperature and proceed as described in steps 9.4.2 to 9.5.4, inclusive.

9.6.3 Calibrate the spectrofluorimeter for $0 \%$ fluorescence with the instrument dark current. As described in 9.7.1, determine the fluorescence of the cyclohexane extract of the most concentrated calibration solution (9.6.1) and set the instrument to read $100 \%$ fluorescence at the fluorescence maximum $(522 \mathrm{~nm})$.

9.6.4 With the instrument calibrated as described in 9.6.3, determine the relative fluorescence $(\%)$ of the extracts of the other two calibration solutions (9.6.1).

9.6.5 Calculate the linear regression relating the mass, $\mathrm{m}$, of $\mathrm{Se}$ in $\mathrm{ng}$ to the percent relative fluorescence, $F$. Plot the corresponding calibration curve, $m=a+b F$.

\subsection{Selenium determination}

9.7.1 Transfer an aliquot of the cyclohexane solution (9.5.4) into a quartz cell and record the fluorescence from 400 to $640 \mathrm{~nm}$, using an excitation wavelength of $375 \mathrm{~nm}$.

The shape of the fluorescence spectrum of the samples should be similar to the spectrum of the standard solutions taken through the entire 
procedure. If digestion was incomplete, the spectrum will be distorted, especially at about $500 \mathrm{~nm}$.

9.7.2 Measure the relative fluorescence in percent at the fluorescence maximum $(522 \mathrm{~nm})$.

\section{METHOD OF CALCULATION}

Calculate the mass fraction, $\omega(\mathrm{mg} / \mathrm{kg})$, of Se in the sample using the formula

$$
\omega=\mathrm{m} / \mathrm{M}
$$

where

$\mathrm{m}=$ mass of $\mathrm{Se}$ in the test portion, obtained from the relative fluorescence (9.7.2) and the calibration curve, 9.6 (ng)

$\mathrm{M}=$ mass of the test portion in $9.4 .1(\mathrm{mg})$.

\section{REPEATABILITY AND REPRODUCIBILITY}

The accuracy and repeatability of the method are indicated in the following table.

\begin{tabular}{|c|c|c|c|}
\hline Material (code) & $\begin{array}{l}\text { Se content } \\
\left(\mu g^{\prime} g\right)\end{array}$ & $\begin{array}{l}\text { Average Se } \\
\text { found" }\end{array}$ & $\begin{array}{l}\text { Coefficient of } \\
\text { variation }(\%)\end{array}$ \\
\hline NBS Spinach (SRM 1570) & $0.04 \pm 0.01$ & $0.036(5)$ & 10.0 \\
\hline NBS Tomato leaves (SRM 1573) & $0.05 \pm 0.01$ & $0.050(5)$ & 13.1 \\
\hline NBS Rice flour (SRM 1586) & $0.4 \pm 0.1$ & $0.361(2)$ & - \\
\hline NBS Orchard leaves (SRM 1571) & $0.08 \pm 0.01$ & $0.084(5)$ & 3.0 \\
\hline IAEA Copepod (MA-A-1) & $3.0 \pm 0.2$ & $3.11(5)$ & 1.6 \\
\hline \multicolumn{4}{|c|}{$\begin{array}{l}\text {-NBS = National Bureau of Standards. USA } \\
\text { IAEA = International Atomic Energy Agency } \\
\text { - Reference values (NBS) or best estimates (IAEA), dry sample basis } \\
\text { "Number of determinations in parentheses. }\end{array}$} \\
\hline
\end{tabular}

\section{NOTES ON PROCEDURE}

Not applicable.

\section{SCHEMATIC REPRESENTATION OF PROCEDURE}

Add $3 \mathrm{~mL} 65 \% \mathrm{HNO}_{3}$ to test portion in decomposition vessel and heat sealed vessel $10 \mathrm{~h}$ at $150^{\circ} \mathrm{C}$ 
Transfer cooled digest to 250 -mL flask, add glass beads,

$2 \mathrm{~mL} 70 \% \mathrm{HClO}_{4}$ and $5 \mathrm{~mL} 98 \% \mathrm{H}_{2} \mathrm{SO}_{4}$.

Heat until white fumes appear<smiles></smiles>

Cool, rinse neck of flask with $5 \mathrm{~mL}$ water and heat to fuming

- $\downarrow$

Cool, add $1 \mathrm{~mL} 30 \% \mathrm{H}_{2} \mathrm{O}_{2}$ and heat to fuming.

Repeat twice<smiles>[AlH2]</smiles>

Cool, rinse neck of flask with $10 \mathrm{~mL}$ water

and heat to fuming $(5 \mathrm{~min}$ )

Cool, add $50 \mathrm{~mL}$ water, $10 \mathrm{~mL}$ EDTA solution and

$7.5 \mathrm{~mL} 25 \%$ ammonia. Adjust $\mathrm{pH}$ to 1.0 with dilute ammonia

Add $5.0 \mathrm{~mL}$ DAN solution and hold at $50^{\circ} \mathrm{C}$ for $30 \mathrm{~min}$

Add $5.0 \mathrm{~mL}$ DAN solution a

In subdued light, cool, transfer to $250-\mathrm{mL}$ separating funnel, add $5.0 \mathrm{~mL}$ cyclohexane and shake for $1 \mathrm{~min}$.

Discard aqueous layer<smiles>[3H][AlH]</smiles>

Wash organic layer with $25 \mathrm{~mL} 0.1 \mathrm{~mol} / \mathrm{L} \mathrm{HCl}$.

Discard acid layer

$\downarrow$

Measure fiuorescence of cyclohexane solution

and determine Se content using standard solution calibration curve.

\section{ORIGIN OF THE METHOD}

National Institute for Public Health and Environmental Hygiene NL-3720 BA Bilthoven

The Netherlands

Contact point: H.A.M.G. Vaessen

Rijks Instituut voor de Volksgezondheid

Antonie van Leeuwenhoeklaan 9

Postbus 1

3720 BA Bilthoven

The Netherlands 